THE SOMALI-DIASPORA EXPERIENCE: A FOCUS ON SOMALI CHILDREN AS CULTURAL BROKERS, AND AS AMBASSADORS OF LANGUAGE AND CULTURE

BY

Abdinasir Farah Mohamud,

B.A (Honours Criminology) Ryerson University, 2016

\author{
A Major Research Paper \\ presented to Ryerson University \\ in partial fulfillment of the requirement for the degree of \\ Master of Arts \\ in the program of \\ Immigration and Settlement Studies
}

Toronto, Ontario, Canada, 2017

(C) Abdinasir Farah Mohamud, 2017 


\section{AUTHOR'S DECLARATION FOR THE ELECTRONIC SUBMISSIONS OF A MAJOR RESEARCH PAPER (MRP)}

I hereby declare that I am the sole author of this Major Research Paper. This is a true copy of the MRP, including any required final revisions.

I authorize Ryerson University to land this MRP to other institutions or individuals for the purpose of scholarly research.

I further authorize Ryerson University to reproduce this MRP by photocopying or by other means, in total or in part, at the request of other institutions or individuals for the purpose of scholarly research.

I understand that my MRP may be made electronically available to the public.

Abdinasir Farah Mohamud 


\title{
THE SOMALI-DIASPORA EXPERIENCE: A FOCUS ON SOMALI CHILDREN AS CULTURAL BROKERS, AND AS AMBASSADORS OF LANGUAGE AND CULTURE
}

\author{
Abdinasir Farah Mohamud \\ Master of Arts, 2017 \\ Immigration and Settlement Studies \\ Ryerson University
}

\begin{abstract}
This paper examines the Somali-Canadian Diaspora experience, and in particular, focuses on the role children in immigrant families play as cultural brokers and as ambassadors of language and culture. Utilizing the literature on language acquisition, this paper's aim is to include the Somali-Canadian Diaspora's voice into the vast literature that exists, which examines the importance of bilingual children, who assist their families in integrating and settling in a host nation. The second component of this paper examines the role language has on identity, and utilizing cultural brokers' language acquisition, investigates how cultural brokers' identity is formed by their bilingualism. The paper posed two research questions:
\end{abstract}

1. In what ways do cultural brokers play a role as ambassadors of language and culture to assist their families in navigating the challenges of a new country?

2. In what ways do the cultural brokers' bilingual abilities inform their identity?

\section{Keywords:}

Cultural Broker, Bilingual child, Acculturation, Familism, Biculturalism, Hyphen-identity, SomaliDiaspora 


\section{Acknowledgment}

I would like to express my heartfelt gratitude to my supervisor, Dr. Francis Hare, who was patient throughout the process of completing my MRP. His guidance and feedback were greatly appreciated. My gratitude as well goes to Dr. Julian Hasford, who agreed to be my second reader, and provided great insight and critical feedback that made the difference in my MRP.

To the five participants of this study, who provided their time and voice, you have my utmost appreciation and your voice was an integral part of this study. 


\section{Dedication:}

I dedicate this work to my family, and especially to my mother, who has shown courage in adversity and always supported me and encouraged my adventures. To my wife, thank you for your love, patience and encouragement, and believing in me, while completing this work. Finally, to the ISS cohort of 2016-2017, I appreciate every one of you and wish you much success in the future, and specifically to the GLC, your support and friendship have been greatly appreciated. 


\section{Table of Contents}

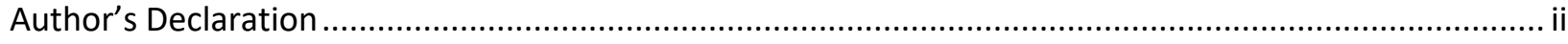

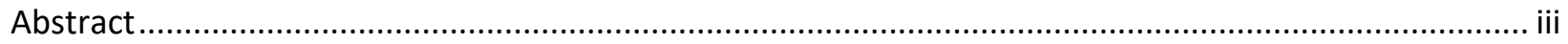

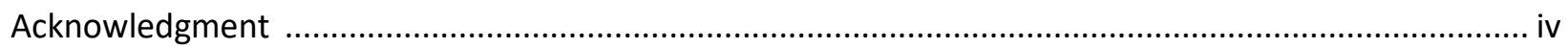

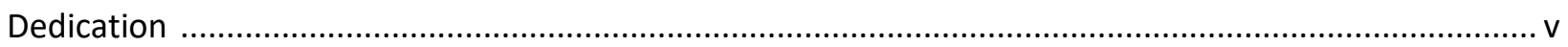

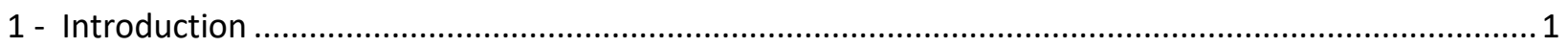

2 - Personal Location: The Researcher's positionality ......................................................................... 3

3 - Research Questions \& Literature Review.................................................................................... 4

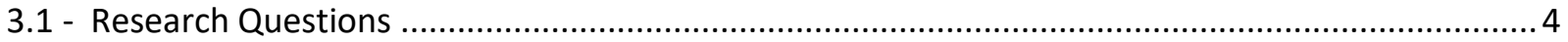

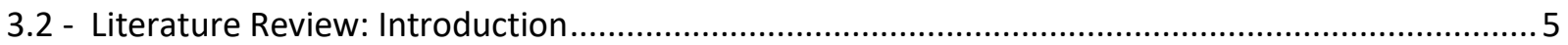

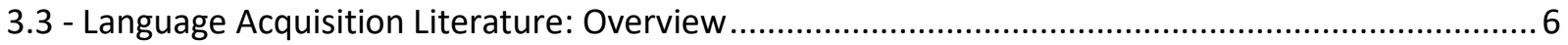

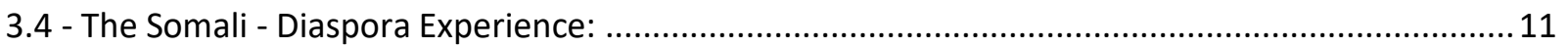

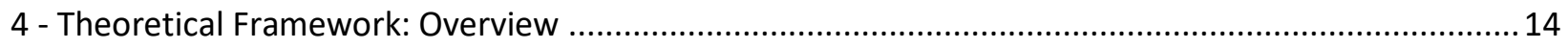

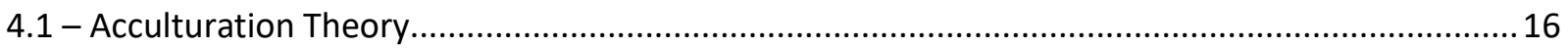

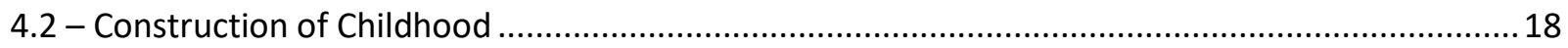

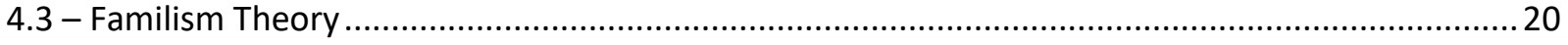

4.4 - Adultification, Parentification, and Role Reversal ..................................................................22

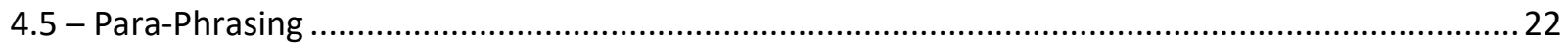

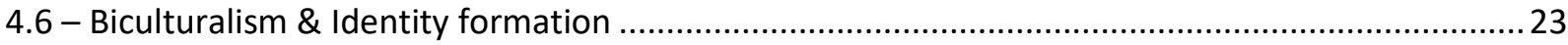

5 - Conceptual Framework: Method, Auto - ethnography, Participants, and Procedure ........................26

5.1 - Method: Qualitative Research; In-Depth Interviewing ...............................................................26

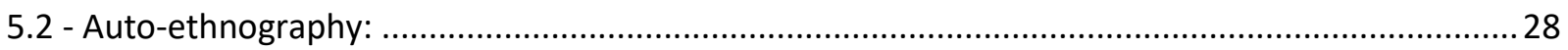

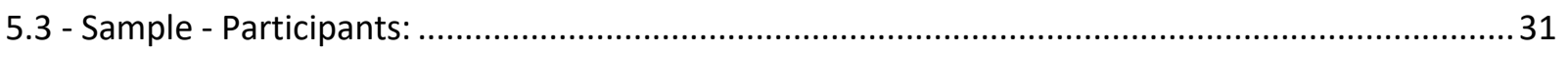

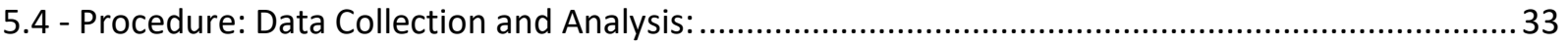

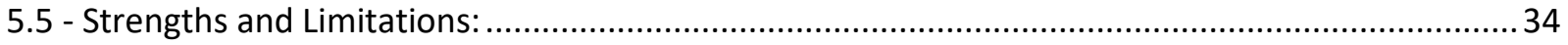

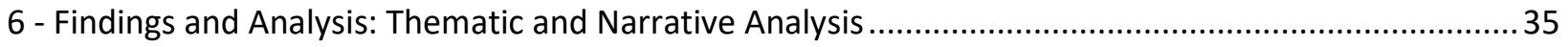

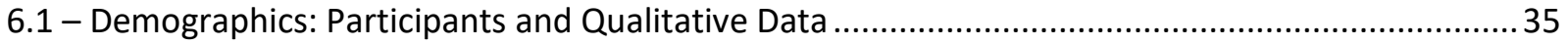

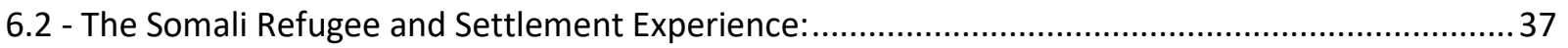

6.3 - Acculturation: Language acquisition of the Somali-Canadian youth ........................................... 40

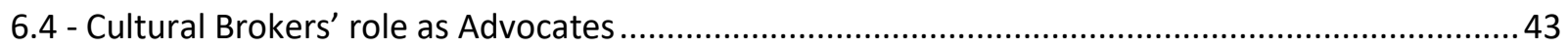

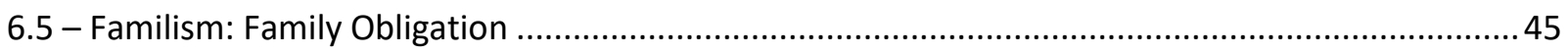

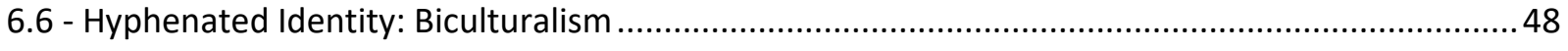

6.7 - Multiculturalism - Identity Discourse …..............................................................................52 


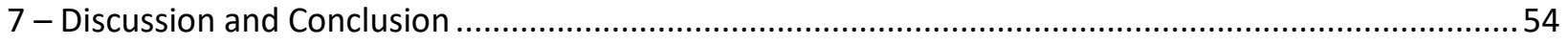

8 - Recommendation - Further Studies .............................................................................................. 56

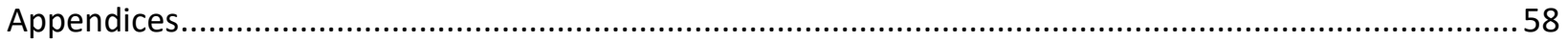

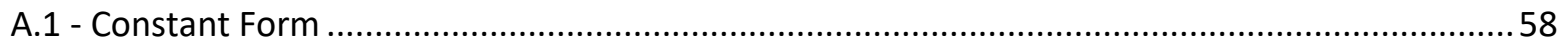

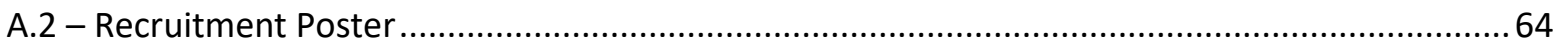

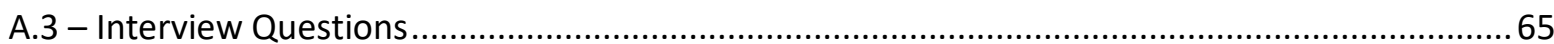

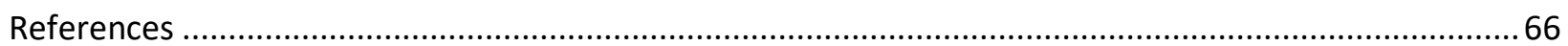




\section{1 - Introduction}

With the introduction of Canada's multiculturalism policy, which has been problematized since then from different vantage points, Canada as a settled land opened its borders and expanded the categories of refugees and immigrants it accepted as candidates. As such, refugees and immigrants from different parts of the world arrived in Canada's borders seeking haven, and for Somalis fleeing civil war, Canada became their new home. However, Somali immigrants faced barriers, from language and culture to being viewed negatively by the mainstream society that was “... rife with panic about immigrants who appeared ... threatening to drain national resources" (Spitzer, 2006, p. 49) and the Somali image was juxtaposed to “... welfare fraud ... [and] undeserving of humanitarian compassion[]" (Spitzer, 2006, p. 49). Although, the problematized image of Somalis has persisted, however, the Somali Diaspora voice is emerging and challenging such negative images and depictions. This study is contextualized within those lenses, and as such aims to discuss the Somali Diaspora experience of integrating and settling into Canada through their children as assets.

The role of children in immigrant families play in the integration and settlement process of their families has received numerous studies, however, certain voices are muted in research. Therefore, this research will explore the Somali-immigrant children's role as translators and interpreters of language and culture. This research will focus on the process through which the Somali-Canadian community utilizes their children as assets of integration. According to Reynolds and Orellana (2009), "when people migrate, [they] become political minorities ... [as] they find their lives structured in ways that forces them to work across language, and places on 
them the burden" (p. 212) and the responsibility "of responding correctly" (p. 212). As newcomers in a host nation that is vastly different from the home nation, immigrant challenges that come with migrating are heightened because of language barriers. As such, children in the immigrant families, and in this research, the Somali-Canadian child become an agent of integration through their language acquisition.

In this present study two expressions, 'cultural brokers' and 'bilingual children', will be utilized simultaneously, to describe the role children play as translators and interpreters of language and culture. The term 'cultural brokers' will be used to refer to Somali-immigrant children's ability to navigate and negotiate between two languages and cultures in assisting their family's integration and settlement process. Further, translation and interpretation although utilized interchangeably elsewhere are being used differently in this present study. In that translation, will refer to translating between two unique and widely different languages, English and Somali, while interpretation relates to the interplay of two different cultures, and how cultural brokers utilized their understanding of both cultures. Cultural brokers act as "mediators between their families and the host culture" (Trickett \& Jones, 2007, p. 140), and translate and interpret the language and the culture to their immigrant parents.

Additionally, the concept of 'bilingual children' will refer to the command of two cultures and languages that the children of immigrant families hold. Therefore, the bilingual child of immigrant families can, "assist their families in a wide range of ways ... they read and decipher ... and they interpret interactions between family members ..." (Weisskirch, 2010, p. 550) and the host nation. As such, children of immigrant families through their role as cultural 
brokers gain trans-cultural abilities, and thus navigate within linguistic and cultural lanes and become experts of two varying systems. To understand why immigrant families, utilize their bilingual children as cultural brokers, this study will contextualize the lived experience of Somali-immigrant families and the barriers they faced in integrating and settling in a host nation that is foreign, in terms of language and culture. "Children stand at the intersection both literally and figuratively as they serve as linguistic and cultural mediators ... speaking languages and language varieties accorded distinct symbolic capital” (Reynolds \& Orellana, 2009, p. 212). Therefore, the bilingual child of the Somali parent is utilized to translate and interpret what seems alien to the parent. The second aim of this paper is to explore through language acquisition how the bilingual child's identity is constructed, and as such, this study will illustrate that Somali-Canadian youth's identity is influenced by their language acquisition.

\section{2 - Personal Location: The Researcher's positionality}

This researcher's positionality motivated this current study. As a first-generation Somali-

Canadian, whose identity has been constructed, deconstructed and reconstructed through the process of fleeing from a civil war at home, being in a limbo in a transit country and finally arriving in a host nation, where my language acquisition became a tool of integration. My experiences as a cultural broker necessitated this research, as the Somali-Canadian voice on language acquisition and Somali-Canadian children as assets rather than as liabilities, was missing from the literature. Additionally, my interest in identity, and in particular, the immigrant identity and how such identity is constructed, led me to investigate the identity formation of cultural brokers, utilizing the literature on language acquisition. 
However, my research journey was met with several limitations, including finding participants. Thus, my initial idea of being an insider, largely due to my Somali-ness, was subjected to a test, as I was not able to find participants initially, and when the interest was there, to commit. Although I attended community events and approached several key informants from several community centers, I was not able to find participants for the first two months of this research. The reasons for the lack of participants and assistance from the key informants was two-fold. First, my initial recruitment started during the month of Ramadan, and as such, I was not able to find participants willing to meet during the Holy month of Ramadan. Secondly, the Somali-Canadian community, although close-knit, is known to be secretive and questions the attention it receives, even from an insider. Although the lack of participants was disappointing, I persevered and continued with the recruitment process.

However, the initial difficulties of finding participants did influence the research process. As such, the focus became more on the topic, rather than recruiting individuals due to my Somali-ness. The recruitment, thus, changed to approaching individuals directly at events and utilizing their contacts. As well as, not depending on the key informants from community centers, once I changed how I conducted the recruiting and thus finding participants for my study, I could recruit enough participants for this study.

\section{3-Research Questions \& Literature Review}

\section{1- Research Questions:}

1. In what ways do cultural brokers play a role as ambassadors of language and culture to assist their families in navigating the challenges of a new country?

2. In what ways do the cultural brokers' bilingual abilities inform their identity? 


\section{2 - Literature Review: Introduction:}

The literature on language acquisition is a great area of research that has received attention from diverse fields in social science, as such this researcher was faced with unlimited sources. This researcher consulted Ryerson University's enormous research database and Google Scholar, to filter through the literature on language acquisition. The initial terminology utilized for this research included but not limited to 'children as translators', immigrant children as interpreters', 'children as social capital' in immigrant families, 'immigrant children and adaptations', 'Somali children as translators for their families', 'Somali Diaspora settlement experiences', 'Somali-Canadian youth and language', and 'Somali parents and children interpreters'. After the first initial research was conducted, a secondary interest in identity and language developed. Thus, the research prompts included 'identity formation of immigrant children', 'language and identity' and 'hyphen identity and migration'. The preliminary results were then utilized to form a better conceptualization of the role that children in immigrant families play in integration and settlement process of their families. As well as, how language and identity are interrelated, and how language influences identity. Further, the inclusion

\footnotetext{
${ }^{1}$ The concept of Social Capital is utilized in this paper as theory that acknowledges the capital that exists within the Somali immigrant family unit, and how immigrant families utilize their children as social capital. As such the concept relates to "... 'the value embedded in the social relationships of individuals or collectives' and on the 'potential resources' flowing from the network of resources possessed by individuals or social units" (Colbert, 2013, p. 3)

"As a social organization of production, the family's chief advantages are not simply tangible products, such as unpaid labor, but also involve the mutual obligation and trust characteristic of solidaristic small groups. It is this latter aspect of the family that we identify with social capital. The production and accumulation of social capital is an intrinsic feature of ongoing social exchanges" (Sanders \& Nee, 1996, p. 233)
} 
criteria for this research included the migration experience of families who did not speak the two official languages of Canada, and as such the experiences of migrants coming from countries that have English or French as their first languages were excluded from the literature review. Additionally, the literature on identity formation of the cultural brokers was limited to how language relates to identity.

\section{3 - Language Acquisition Literature: Overview}

Language acquisition researchers have referred to "these children ... as language

brokers" (Cila \& Lalonde, 2015, p. 498), however, in this present study, the participants will be referred to as cultural brokers, to acknowledge the duality of their role. Children of immigrant families not only translate the host nation's language for their parents and families, they also act as a conduit of integration throughout their families' settlement process, by interpreting the culture of the host nation. Through migration, according to Ladilova (2015), migrants find their language and culture marginalized in the host nation and "find themselves in a minority setting []" (Ladilova, 2015, p. 180), and cultural brokers mitigate difficulties of migration through their language acquisition. Therefore, to have a full grasp of what children in immigrant families do, we need to acknowledge the duality of their role. In addition, research and researchers on language acquisition and cultural brokers has mostly emerged from the United States and entirely focused on the Latino-American experience, however, "there has been a growing scholarly interest in extending our understanding" (Cila \& Lalonde, 2015, p. 498) of cultural brokers and their importance to the integration and settlement process of their families. Therefore, researchers have added other immigrant voices to the literature on language 
acquisition, and specifically, the focus has been, according to Cila and Lalonde (2015), on Russians, Chinese, and Germans. In addition, Canadian language acquisition researchers have extensively focused on several Asian-Canadian communities' experience of utilizing cultural brokers as a conduit of integration. The purpose of this study is to add the Somali Diaspora experience of utilizing their children as cultural brokers. The Somali Diaspora experience, although not unique, is absent from the literature.

Language acquisition research on children of immigrant families as a conduit of integration in the settlement process of their families has received increased attention from social science researchers interested in varying processes of migration, child development and, parent and child relationship. However, according to Morales and Hanson (2005), language acquisition literature was scarce and did not "emerge in earnest in the literature until the mid1990s" (p.489). Although, children of immigrant families have always acted as a conduit of integration for their families while settling in a new host nation. The increased attention that these population has received in the last few decades can be attributed to globalization. Globalization as a means of converging the world together, and in the process of and consequences of globalization, mass migration of people, with diverging pull and push factors, resulting, according to Suarez-Orozco and et. al (2011), the restructuring of societal demographics. Children of immigrant families are a big part of migration, as "the children of immigrants are the fruit borne of immigration ...[and] immigrant-origin children are a fastgrowing sector of the youth population in diverse countries the world over including ... Canada" 
(Suarez-Orozco, Darbes, Dias, \& Sutin, 2011, p. 313), thus their role as conduits of integration has received an increased attention from social scientists.

Additionally, the focus on early studies on children of immigrant families has been on the “... prevalence of language brokering among immigrant families" (Morales \& Hanson, 2005, p. 489), and how often their role as a conduit of integration is utilized. Although, the parameters of the research on these population has been expanded to include how their identity is formed through their role as translators, an interest in this present study, as well as their bilingual development, however, "it appears ... that the area of ... brokering is divided into two different camps" (Morales \& Hanson, 2005, p. 490) with varying conceptualization of cultural brokers. On the one side, researchers who view cultural brokering as a positive experience "believe that children serving as language brokers find the experience enjoyable and it helps them learn more about their first and second language" (Morales \& Hanson, 2005, p. 490) and in the process become bilingual and gain transcultural abilities. Insofar as, these children gaining adequate knowledge and grasp of two languages and cultures to be able to act as social capital for their families. On the opposing lens, researchers who view cultural brokering as a negative experience, view children of immigrant families' role as cultural brokers, as "stressful and a burden" (Morales \& Hanson, 2005, p. 490) on these children.

These researchers, therefore, question why professional interpreters are not utilized instead of children, who in the process of translating might make "translation errors ... [as well as] the possibility of interview material being sensitive in the context of the language broker's particular relationship with the speaker, [and] the imposition of responsibility" on the cultural 
brokers. However, a study by Cline and Crafter (2011) on cultural brokering in school setting noted that "a professional interpreter is independent, impersonal and detached" (p. 4), while a cultural broker is emotionally involved, personal and conscious about the result of the brokering. Additionally, Hall and Sham (2007) on their study of language brokering as a young people's work, explored an essential element to why cultural brokers are utilized, noting that "one ... factor might be the extent to which families might be willing to discuss problems with other community members. Privacy and face are very significant to [immigrants] families, and this may dispose families to rely on children within the family than to readily seek assistance from other community members when problems arise". (p.27) Although Hall's and Sham's study was focused on Chinese families' utilization of cultural brokers, it could be applied to most immigrant communities, who might feel their 'problems' might be broadcasted to the public if they use a community translator and interpreter. Though, according to a report by OCASI (2016), such services are "at much-reduced capacity ... [because of] defunding" (p.5) and might not be readily available to all immigrant communities.

Therefore, using cultural brokers is an attractive option, which comes with ensured privacy, and in the process, creates a sense of normalcy for immigrant families as it is their children who are taking the lead in the integration process. Studies have also shown that "connectivity is the primary way by which non-Western individuals and cultures organize relationships, in contrast with the Western focus on individualism" (Dorner \& Orellana, 2008, p. 19). Accordingly, immigrant families are interdependent on each other and "one's dependence on relationships with others are valued throughout development more so than one's growing independence" (Dorner \& Orellana, 2008, p. 19). Essentially, making cultural brokering part of being in a family unit and not extraordinary. 
Furthermore, Weisskirch (2005) connects cultural brokers' bilingual ability with forming "close ties to the native and host culture" (p.288), ultimately resulting in the bilingual child's "feelings of self-confidence because of the experiences of communicating in two languages" (p.288). Cultural brokers' ability to navigate within two cultural lanes affirms their identity and belongingness. Subsequently, brokering "may contribute to the formation of a strong ethnic identity ... [and] for ... ethnic minorities ... an ethnic identity coincides with the formation of the identity as a whole" (Weisskirch, 2005, p.289). Thus, language acquisition for a cultural broker contributes to the formation of their identity, as "language is not a monolith ... instead, it is a complex set of social practices intertwined with identity formation, power inequalities and social belonging" (Suarez-Orozco, Darbes, Dias, \& Sutin, 2011, p. 315). Language, thus "operates as a medium for the construction of the social world and means by which social relationships are ... constituted" (Anderson, 1999, p. 18). In other words, through language acquisition children of immigrant families' identity is constructed through environment demands of the host nation and their role as cultural brokers. Somali immigrant children, thus, through their duality reduce the language barriers their families face, as "in general, most Somalis spoke neither English nor French when they arrived" (OCASI, 2016, p. 3) and since their children learn the host nation's language faster, they become the voice for their parents. However, issues of “... language is a double-edged sword. The requirement of the host society dictates the languages that are crucial to functioning in that society" (Lansford, 2007, p. 47) and immigrants whose language is different from the host nation's language are disadvantaged; thus, it is the children of immigrant families that become the voice for their families and bridge the gap. 
Migration as a concept is "a very complicated global issue, no one has yet provided any ... basis which can be universally ... accepted as standard" (Sinha, 2005, p. 403) that defines what it entails. However, migration as a human consequence of unrest and conflict, and as a "movement of people across borders" (Cholewinski \& Taran, 2009, p. 1) and international waters can be said to involve "the displacement of people and their arrival in other lands inevitably reflect - and pose - conflicts of needs and interests" (Cholewinski \& Taran, 2009, p. 1). Therefore, migration as a "perpetual movement ... [of] human beings" (Butler, 2001, p. 189) is an arduous process "in which people relocate definitively" (Butler, 2001, p. 202) and attempt to start new lives in their host nations. However, migrating and settling in a new country is further complicated, as issues of integrating and settling are magnified when there is a language barrier. Research on language acquisition has shown that children of immigrant families learn the language and culture of the host nation faster, and thus act as cultural brokers. As cultural brokers, children are utilized as a social capital and are "there to support someone ... [and] parents will often look to their children to act as ... brokers on their behalf" (Cline \& Crafter, 2014, p. 4). Essentially, cultural brokers "act as intermediaries between ...[their] parents" (Cline \& Crafter, 2014, p. 4) and the host nation.

\section{4 - The Somali - Diaspora Experience:}

The Somali Diaspora experience in Canada is a refugee experience, since "most Somalis entered Canada as refugee claimants" (OCASI, 2016, p. 1) fleeing from the civil war that erupted and displaced millions of Somalis inside and outside of their home country. A refugee, as 
defined and enacted by the UNHCR in the 1951 Convention relating to the State of Refugees and its 1967 Protocol, is;

\begin{abstract}
"a person who owing to well-founded fear of being persecuted for reasons of race, religion, nationality, membership of a social group or a political opinion, is outside the country of his/her nationality and is unable, or owing to such fear, is unwilling to avail himself [and herself] of the protection of that country; or who, not having a nationality and being outside of the country of his former habitual residence as a result of such events, is unable or, owing to such fear, is unwilling to return". (p.3)
\end{abstract}

As such, Somali refugees unable to return due to a well-founded fear of persecution, "led to a large exodus of refugees ... fleeing to Canada and other countries" (Scott, 2001, p. 19). Somalis, however, have since then also entered Canada through "family reunification" (OCASI, 2016, p. 1), because of familial connections. The eruption of civil war in 1991 as the result of the "downfall of regime ... [with] human rights abuses" (OCASI, 2016, p. 1) caused the perpetual movement of Somalis, who in an effort to find safety, security and a sense of belonging, arrived on 'strange lands' that not only made their language and culture odd but marked their bodies as indifferent. The identity of the Somali Diaspora, therefore, was largely constructed through a colonial gaze that problematizes difference and thus 'Others' those it sees as indifferent. Moreover, Canada, as a colonized and settled land, "racialized groups as a whole face several disadvantages" (Scott, 2001, p. 22) and as such the narrative and image of Somalis in Canada is one of 'alien', the ultimate 'Other'. "'Otherness' ... [as] the site of difference and [where] the repository of our fears and anxiety" (Rutherford, 1990, p. 10) exist, marginalizes and categorizes racialized and problematizes certain communities. However, "the story of Somalis 
is not only one of discrimination and settlement challenges, but one of resilience as well" (OCASI, 2016), and cultural brokers as a conduit of integration are part of that resilience.

The family, as noted by Abdullahi (2001) is an important dimension of the Somali Diaspora experience, as the family unit plays a meaningful part in the formation of an identity of the individual. Conversely "kinship forms the core of the Somali" (Spitzer, 2006, 47) identity, and as such the family in the Somali Diaspora context is one of attachment, and maintaining attachment. The Somali family, in addition, is generally traditional and hierarchical, and as such the "children are subordinate to their parents" (Scott, 2001, p. 23). Although, subordination comes with a negative connotation, however, in the Somali context, what it essentially entails is respecting of the parents and elders in general, and seeking their "approval ... and to follow their guidelines" (Scott, 2001, p. 23). The universal convention in the Somali family, thus, as with many traditional immigrant families, is that parents are held in high regard with utmost respect. Although intergenerational differences might arise, since "Somali youth [are] faced with two cultures" (OCASI, 2016, p. 5) with contradictory views, however, most Somali youths utilize their two-identities that embody their bodies as an advantage. In addition, "immigrants arriving in Canada find themselves in a social environment that is confusing, frustrating, ... challenging" (Frideres, 2002, p. 12), and ultimately experience a fragmented existence within the host nation. However, immigrant families tend to fuse together and each member of the family plays a role in the integration process. As such, cultural brokers in exercising their language and cultural fluency, create a comfortable safety zone, where they become the social capital for their families, also in the process resist their 'Othered' image and thus construct 
their own identities through language and culture. Identities are argued to be "shaped not only by recognition, but also its absence" (Coulthard, 2007, p. 442), in that marginalized groups "can suffer real damage, real distortion, if the people or society around them mirror back to them a confining" (Coulthard, 2007, p. 442) image of their bodies.

Therefore, one of the purposes of this study is to understand how cultural brokers' identity is formed through brokering, as identity is "a production which is never complete, always in process and always constructed within, not outside, representation" (Hall S., 1990, p. 222). Insofar as identity formation of cultural brokers can be juxtaposed to their social location and experiences within the host nation. As Hall (1990) inserts, "[d]iaspora identities are those which are constantly producing and reproducing themselves anew, through transformation and difference (p.235). Therefore, by studying Somali youth's identity formation through their role as a conduit of integration, this study will add to the growing voices of Somali Diaspora, in dismantling the problematized image of Somali Canadians.

\section{4 - Theoretical Framework: Overview}

Within language acquisition literature, researchers have established theoretical frameworks to discuss the foundations of cultural brokering, and how cultural brokers become an important dimension of the integration and settlement of their families. The vast body of literature on language acquisition discuss the role that children of immigrant families play in the integration and settlement process of their families through several interlocking theoretical frameworks. These theoretical frameworks provide a space to voice the difficulty of migrating to a host nation that is vastly different from the home nations of most immigrants, and how 
cultural brokers are utilized as agents of social capital. These frameworks include the Acculturation theory, Familism theory, the interrelated theories of Adultification, Parentification and Role Reversal, and Para-Phrases and Identity formation through Biculturalism theory. Theoretical frameworks are utilized to delineate the role of cultural brokers in immigrant families, and although some frameworks problematize that role, there is a general agreement that cultural brokering is a reality for children in immigrant families. Insofar as, children in immigrant families' role as ambassadors of language and culture is "... embedded in the everyday routines of immigrant communities" (Eksner \& Orellana, 2012, p. 198), and accepted as the norm in immigrant families.

Migration, as noted earlier, comes with a magnitude of challenges, and monolingual immigrant families face barriers as new immigrants, whose language and culture is different from the host nation's language and culture, as such "... value conflicts, prejudice and lack of access to supports" (Hua \& Costigan, 2012, p. 894) are usually magnified when an immigrant lacks language proficiency of the host society. Immigrant families, thus, use their bilingual children as a social capital as their children "... are immersed in mainstream educational institutions, which enables their mainstream language and cultural competency, which in turn facilitates their role" (Cila \& Lalonde, 2015, p. 499) as cultural brokers. Albanese (2009) further notes, as children of immigrant families' pick up the host nation's language they find themselves in a position to translate for their "parents at ... grocery store, bank, and government offices [which is] for many immigrant children ... not so unusual" $(2009$, p.135). Therefore, to effectively function in the host nation, monolingual parents rely on their bilingual 
children. The literature on language acquisition employs the acculturation theory as a

framework to examine the notion that children of immigrant families learn the host nation's language at a greater rate and thus act as cultural brokers for their families. The acculturation theory is important in this study as it forms the process children of Somali immigrant parents go through to become cultural brokers, and will be utilized to discuss the identity formation through language acquisition.

\section{1-Acculturation Theory}

The acculturation theory was first defined as "a sociological process in which cultural change resulted from contact between two autonomous and independent cultural groups" (Smokowski, Rose, \&\& Bacallao, 2008), in which one group's culture dominates the other group's culture. Insofar as immigrants are pushed to adapt and learn the host nation's language and culture to integrate into the existing society. Acculturation theory is the lens that most often employed in literature on language acquisition, and has been utilized by several researchers to describe the ability of cultural brokers to "progressively adopt the norms, beliefs, and values of the host society" (Tse, 1996, p. 492), and in the process of acculturating learn the language of the host nation. Further, the acculturation theory is "characterized ... as flowing from contact between dominant and nondominant groups ... eventually resulting in adaptations by one or both of the groups" (Smokowski, Rose, \& Bacallao, 2008). However, with migration, the dominant group is the host nation, and immigrants find themselves in nondominant position and as result are "... strongly influenced to take on the norms, values, and behaviors espoused by the dominant group" (Smokowski, Rose, \& Bacallao, 2008). Therefore, 
since children of immigrant families acculturate faster than their parents, and thus become bilingual, in the sense of retaining their mother tongue and attaining proficiency in English, they become the lens their parent's access and integrate into the new society. Bilingual children of immigrant families "contribute to family resilience by serving as both translators for their parents and cultural brokers for the family" (Smokowski, Rose, \& Bacallao, 2008), and as such become the conduit of integration.

Additionally, the acculturation theory as an "overall process of cultural involvement ... has two important subcomponents-(a) the extent to which the acculturating individual or group retains culture-of-origin involvement and (b) the extent to which host culture involvement is established" (Smokowski, Rose, \& Bacallao, 2008). Children of immigrant families retain the home culture through their parents and families while adopting and getting involved in the new culture through school and being open to acculturate into the new culture. Cultural brokers' "acculturation involves not only changes but also continued development and overlaps with the process of ... socialization" (Genkova, Trickett, Birman, \& Vinokurov, 2014) both at home and outside of the home. Therefore, bilingual children in immigrant families as agents of integration navigate between two cultural lenses and become experts of both cultures and in turn act as a conduit of access for their parents through cultural brokering. The process of acculturation although linked to assimilation is different from assimilation since cultural brokers acculturating is a normal process that takes place without coercion, whereby assimilation is associated with coercion. 
Furthermore, cultural brokers' role as social capital can be viewed as "one of the many ways that immigrant children contribute to their household functioning ...[and] fulfilling other family responsibilities" (Trickett \& Jones, 2007, p. 143). Immigrant families migrate from countries with "different values, norms, and behaviours ... and they are expected to function within a different cultural framework" (Bauer, 2016), effectively or otherwise considered as failures. Therefore, the ability of children in immigrant families to acculturate reduces the impact and stresses of migration. As cultural brokers integrate into the host society, their role as ambassadors of language and culture is magnified as "child interpreters ... [become] responsible for the acculturation of their parents and families" (Tse, 1996, p. 495). Moreover, newcomers are expected to take on the host nation's societal norms, however, "when a family initially moves into a new country and culture, its members ... will be less familiar with the culture and will need to rely more on each other" (Buriel, 1998, p. 288). With immigrant families, cultural brokers embody that role and act as mediators between their family and the host society.

\section{2 - Construction of Childhood}

Adapting to and integrating into "... life in a Western country for ... [most] immigrants are often accompanied with stress and hardship" (Hua \& Costigan, 2012, p. 894) and face barriers, however, cultural brokers' role as conduits of integration eases the stress and hardship immigrant parents face. Westernized ${ }^{2}$ notions of who and what child is and should be involved in complicates the role cultural brokers play as agents of integration. The definition of a child in

\footnotetext{
${ }^{2}$ In this paper, the Westernized notions of childhood is related the North American (Canada and the United States of America) construct of childhood.
} 
immigrant families, however, is vastly different from the Westernized notion of a child. Insofar as, the role of a child in immigrant families is viewed differently in terms of what is expected from a child in a Westernized setting, thus in the mainstream society "child language brokering appears to challenge contemporary views of 'normal' human development" (Cline, Crafter, O'Dell, \& de Abreu, 2011, p. 209) of a child. Concerns of child brokering in the mainstream society are linked to the construction and definition of a child, and thus cultural brokers are problematized as they are viewed as antithesis to the "ideological construction of a 'proper' childhood, or 'childhood as a time of innocence' whereby the child is free from worry and maintains an absence of knowledge" (Bauer, 2013, p. 206) of family issues.

However, the construction of childhood in the mainstream society is based on the privilege of accessing resources that immigrant families are not able to without the help of cultural brokers. Westernized notions of childhood have framed "... childhood to be a period in the life course that is absent of adult responsibilities and behavior" (Burton, 2007, p. 330). That notion of childhood is a luxury that monolingual immigrant parents cannot avoid as cultural brokers are a "source of support for their parents that may help facilitate parents' acculturation to host society" (Bauer,2013, p. 206) as their role as cultural brokers assist in the integration of their families into the host society. Children of immigrant families are thus utilized as a social capital and play a key role in their families as "they help to make it possible for their parents to live, eat, shop, and otherwise sustain themselves as workers, citizens and consumers in the host nation" (Bauer, 2013, p. 214). Language thus "becomes a form of social action, which may sometimes bring about certain practical ..." (Bauer, 2013, p. 208) change as children of 
immigrant families utilize their bilingualism as a tool of difference, where their families' voices are given the space and outlet to access resources and their integration and settlement made that much easier. Cultural brokers' language abilities can be viewed as a form of power, insofar as, cultural brokers utilizing their language power as "a functional task to aid the family and particularly the parents" (Weisskirch, 2010, p. 80) and "in the process of doing so, [cultural brokers] ... explore and resolve a sense of ethnic identity, and enhance their sense of selfefficacy" (Weisskirch, 2010, p. 80). Language, thus, becomes a form of power that cultural brokers employ to resolve several interlocking aspects of integration and settlement of their family and the development of their identity.

\section{3 - Familism Theory}

Notions of family obligation and the utilization of cultural brokers as agents of integration have been viewed through the lens of familism theory. Language acquisition researchers have utilized the familism theory to explain the "strong sense of attachment and obligation that immigrant children and children of immigrants feel toward their parents" (De Ment et al., 2005, p.260). This aligns with the interdependence and collectivistic nature of familistic cultures, where as noted by Casteneda (2005), the interests of the family unit are prioritized over individual interests. Therefore, in immigrant families, the needs of the family in the process of integrating and settling into the host nation take precedence over individual needs and wants. Insofar as the concept of familism "presupposes the primacy of the family over the individual interests of its members ... as familism involves a deeply ingrained sense of the individual being inextricably rooted in an extended family system and is commonly 
regarded as the most influential factor" (Smokowski, Rose, \& Bacallao, 2008, p. 297) in familistic cultures. These cultures have "a strong sense of family obligation, which involves a perceived need or duty to help and support one's family members" (Hua \& Costigan, 2012, p. 895). Thus, the role of the ambassadors of language and culture as cultural brokers are perceived as a typical part of being in a family unit.

The Familism theory is strongly linked with respect for elders as noted by Hua and Costigan (2012). This theoretical framework further explains the "interactions and society support patterns found in immigrant" (Valenzuela, 1999, p.722) families, where existing networks, in this case, cultural brokers, are utilized to integrate and settle in the host nation. Consequently, the role that immigrant families assign to the cultural brokers' is to take the "responsibility for making decisions with English-speaking agents that affect their entire" (Buriel, 1998, p. 284) family unit. This allocation of parental power and the empowerment of the bilingual child can be viewed as either a positive, character building task or viewed through a negative lens, where the increased levels of independence of the cultural broker are problematized. Insofar as some researchers connotating Westernized societies “... favoring [of] individualism often clashes with ... [immigrant] parents' adherence to traditional values emphasizing family cohesion, familism, and parental control (Smokowski, Rose, \& Bacallao, 2008 , p. 297). Consequently, cultural brokers' role in the family is problematized through three interrelated theoretical frameworks of Adultification, Parentification and Role Reversal, which researchers have used to problematize the role that the children of immigrant families often take on as being an adult role in the family. 


\section{4-Adultification, Parentification, and Role Reversal}

The Adultification framework defined as "children taking on extensive adult roles and responsibilities prior to their developmental readiness to do so" (Cheng, 2012, p. 18), suggests a negative perception of cultural brokers, and their role as translators and interpreters for the immigrant families. The Parentification framework essentially suggests that the child becomes the parent in the relationship, as their role as cultural broker provides them with enough autonomy to run the family, ultimately resulting in conflict within the family unit. Whereby the role reversal framework deals with "a relationship disturbance in which a parent looks to a child to meet the parent's needs for comfort, parenting, intimacy, or play while the child attempts to meet these needs" (Cheng, 2012, p. 18). Conversely, these frameworks are based on the dominant Western understanding of children and childhood. In immigrant families, as Pulido (2003) notes, the role of cultural brokers as ambassadors of culture and language is treated as nothing special. Furthermore, the researchers that utilize these frameworks, which are negatively correlated with children acting as cultural brokers, argue that family dynamics change when the child takes on an adult-like role.

\section{5 - Para-Phrasing}

Another framework employed in the literature on language acquisition, and developed by Orellana and et al. (2003), is the concept of 'Para-Phrasing", which signifies "what children do when they 'Para-Phrase' things for others, in order to accomplish a social goal” (Orellana, Reynolds, Dorner, \& Meza, 2003, p. 15). This concept of children as 'Para-phrases' goes hand in hand with the theoretical frameworks that problematize the utilization of bilingual children, as 
it questions how and what children translate for their families, and whether children are Paraphrasing correctly. For this purpose, it has been argued that "Para-phrases may act in capacities for which they have no formal preparation and in which their qualifications are open to questions and critique" (Roche, 2014, p. 214). However, the concept was initially developed to indicate the importance of cultural brokers, and their ability to navigate between two distinct languages to find the commonality and thus translate for their nonaffluent parents. Conversely, cultural brokers' role as 'Para-Phrases' can be viewed as a character building task, since it involves the process of navigating between two worlds through language acquisition, and utilizing their skills in both languages and cultures.

However, this concept can be argued to point to the Adultification of bilingual children, since it involves, "children speaking to and for adult authority figures" (Dorner, Orellana, \& LiGrining, 2007, p. 455). As Cheng (2012) notes, bilingual children in adult roles become problematic as "the expectations of the child become greater" (p. 17) and the immigrant parent becomes reliant on the bilingual child. Language and identity, thus, become inherently linked, as cultural brokers identity is influenced by their role as ambassadors of language and culture. As such, the identity formation of cultural brokers is a key area to investigate.

\section{6 - Biculturalism \& Identity formation}

Cultural brokers' process of identity formation is an area of research that has recently received attention from language acquisition researchers and juxtaposes identity formation with cultural brokers' role as translators and interpreters of language and culture. Through 
cultural brokering children in immigrant family formed their bicultural identity, as their identity, according to Penalva (2017);

"often entails the juggling of competing allegiances and attachments situated within two cultural worlds, they must define themselves in relation to multiple reference groups (sometimes in two countries and in two languages) and to the classifications into which they are placed by their native peers, the schools, the ethnic community, and the larger society ... and often entails the juggling of competing allegiances and attachments". (p.439)

Further, in this study, the identity formation of cultural brokers will be demarcated through the conceptualization of biculturalism. Biculturalism represents, as noted by Portes and Rumbaut (2001 \& 2006), the comfort and proficiency of cultural brokers who understand both their own heritage and the culture of the host nation. Biculturalism as a theoretical framework is an important and fascinating field to contribute to, and it involves the discussion of ideas around identity formation and how children from immigrant families navigate between two worlds. This includes the transcultural abilities that immigrant children gain as part of their role as ambassadors of language and culture, which helps them navigate between two cultural systems and become experts of two varying values and sets of beliefs. The role of cultural brokers is extremely important to the literature on children of immigrant families, because their role as ambassadors of language and culture is all-encompassing, and plays a significant role in the settlement experience of their families. Moreover, the role of bilingual children goes beyond translating and interpreting, as Valenzuela (1999) notes, cultural brokers also act as tutors, advocates, and surrogate parents. These roles denote the importance of ambassadors of culture and language to immigrant families.

Literature on identity formation views identity, 
"as a social process ... a journey that is never finally achieved, but continually created as it changes and shifts ... [since] people, at any given moment, are actively constructing their social identities, rather than passively living out some cultural prescription for social identity ... identity, [thus] is dynamic, both spatially and temporally ... [and] children adapt and transform the cultural recipe". (Peñalva, 2017, p. 439)

Therefore, cultural brokers ability to adapt to new "social environments that are confusing, frustrating and challenging" (Frideres, 2002, p. 12) enables their role as ambassadors of language and culture in their families' integration and settlement process. Additionally, Kabir (2013) notes, identity can further be conceptualized as

"... the condition of being oneself (and not another). Arguably it is a fluid process that is shaped according to circumstances and opportunities. Identity may depend on the family one is born into, the culture and religion one belongs to, one's community and one's life experiences. Identity is both individual and group oriented". (p. 528)

Cultural brokers identity formation is fluid and continuingly being shaped by their experiences as a conduit of access for their families. Consequently, children in immigrant families "negotiate a sense of self within and across a range of sites at different points ... and through language" (Norton, 2010, p. 2) their identities are shaped and reshaped. Additionally, children of immigrant families can acclimatize and thus become immersed in the host nation as their immigrant parents have at the time of migration "established their self-identity ... [and] tend to retain ... and maintain their previous identities as the best strategy for coping with the new super-culture" (Frideres, 2002, p. 16). Cultural brokers ability to retain and attain two languages and cultures is used as a strategy for inclusion and belonging to the host nation and in the process forming cultural brokers identity.

Identity formation as a social process is "... constructed through a complex interaction between individuals and their society" (Frideres, 2002, p. 19), and children of immigrant 
families through their "involvement in many of the family's social, economic and administrative activities" (Hall \& Sham, 2007, p. 19) construct their identities as "language is ... theorized not only as a linguistic system but also as a social practice in which experiences are organized and identities" (Norton, 2010, p. 2) formed. Further, migration, language, and identity are interrelated as they relate to concepts of belonging and fitting into a host society. Insofar as the migration process "highlights ... human struggle because it is more dramatic and more profound for an individual ... because the losses involved in relocation seem total and include the loss of language" (Czubinska, 2017, p. 163). Consequently, immigrant families utilizing their bilingual and bicultural children as agents of integration lessens the struggles that come with migration. Language, therefore, Orellana and et al (2003) state, is a tool for navigating socially, constructing meaning and displaying identity.

After reviewing the language acquisition literature, and discussing the theoretical framework on cultural brokers, three theoretical frameworks will be utilized in this study to add the Somali voice into the vast literature. Thus, acculturation theory, familism theory, and biculturalism theory will play a part in discussing the Somali-Canadian experience.

\section{5 - Conceptual Framework: Method, Auto-ethnography, Participants, and Procedure}

\section{1 - Method: Qualitative Research; In-Depth Interviewing}

This study was approached from the lens of qualitative methodology, to investigate the role of cultural brokers in the settlement process. As such, qualitative research methods of auto-ethnography and interviewing was utilized. To better understand the role cultural brokers, 
play in the integration and settlement process of their families, and how their role plays a part of their identity formation, this study utilized a qualitative research method. Qualitative methodology as an exploratory research method that aims to gain an insight of the lived experiences of individuals, was implemented to understand cultural brokers' perspective and knowledge of the world they inhabit. The aim of this research was to add the Somali voice and narrative into the vast literature on language acquisition and utilizing qualitative research method allowed for the focus on personal meanings of the social world. To that end, interviews as "the most widely used method employed in qualitative research" (Edwards \& Holland, 2013, p. 1) was utilized to get an insight into the lived experiences of cultural brokers and gain an insider perspective.

More specifically, the qualitative data was collected through in-depth interviewing using semi-structured questions, to elicit cultural brokers' perspectives on their role as a conduit of integration, and how their identity was formed through brokering. As such this researcher conducted five in-depth semi-structured interviews. In-depth interviewing was chosen as a data collection device, because it allows for a conversational tone, where the researcher and participants as equals are interacting and through the interview, according to Johnson (2001), creating a mutual intimacy and respect, where the conversation can flow through without any restrictions. The aim is to explore and capture the participants' meaning on their lived experiences as a cultural broker. Additionally, Johnson (2001) states that in-depth interviews;

"rarely constitute the sole source of data in research ... [as] more commonly, they are used in conjunction with data gathered through such avenue as lived experiences of the interviewer as a member ... in what is being studied". (p.104) 
This researcher's personal narrative and location as a Somali-Canadian cultural broker in both the transit country and the host nation has been used in conjunction with the study's participants. Additionally, since in-depth interviews "allow for the interviewer ... [to] use all of the personal narrative resources at their disposal to establish open and trusting relationships with respondents" (Gubrium \& Holstein, 2001, p. 28). This researcher's experiences as a cultural broker were utilized throughout the interviews as a tool for establishing commonality and extracting more information from the participants.

The duration of the interviews varied, lasting from forty-five minutes to one hour. The interview questions were constructed in such way that this researcher was able to extract information on the frequency of cultural brokering, places where the brokering took place, whether the participants felt they assisted in their families' integration and settlement process through their language acquisition, as well as how their identity was formed through their role. Although, this research was not aimed at exploring narratives of the black body and how 'blackness' is problematized in a multicultural state, however, throughout the interviews, discussions on the Somali Diaspora identity formation resulted into participants sharing their views on identity and 'Otherness'. Through the interviews, a better understanding of cultural brokers lived experiences were gained.

\section{2 - Auto-ethnography:}

The auto-ethnography piece was incorporated to contextualize the researcher's personal narrative and location within the study. Auto-ethnography as a research method is “... whereby the author/researcher draws on his or her own experiences written in the form of 
personal narratives to extend new knowledge" (Jensen-Hart \& Williams, 2010, p. 451) and to add to the existing data. Auto-ethnography as "a reflexive exploration of ... personal experiences" (Pace, 2012, p. 5) was useful method to recall the researcher's experiences as a cultural broker and to critically examine personal biases. Therefore, as a cultural broker, autoethnography was a useful tool, as it allowed for the interrogation of this researcher's lived experience as a cultural broker, it also acted as a bracketing exercise. Bracketing as a method in qualitative methodology was utilized;

“... to mitigate the potential deleterious effects of unacknowledged preconceptions related to the research and thereby to increase the rigor of the project. Given the sometimes-close relationship between the researcher and the research topic that may both precede and develop during the process of qualitative research". (Tufford \& Newman, 2010, p. 81)

As such the process of taking an auto-ethnography ${ }^{3}$ approach in this research, before the data analysis is to minimize my voice and to be able to critically examine the participants' data on their own merit.

My first memory of being a cultural broker was in a Refugee camp in Kenya, where I assisted an Eedo (Somali term for Aunt - not necessarily blood related, sign of respect) to communicate with a camp's official. I remember feeling a sense of pride, here I was six years old and I could communicate in two different languages and acted as an intermediary for two adults. Although, I do not recall what the conversation was about or the result of my brokering, my sense of pride endures to this day. My family and I left Somalia when the civil war broke out and we were privileged enough to flee the country and seek safety and protection in Kenya. As

\footnotetext{
${ }^{3}$ Auto-ethnography is being used in this research as a reflective piece and as a bracketing exercise.
} 
the literature review on acculturation revealed, children of immigrant families learn the language of the host nation faster, and as such, I was able to grasp the language and culture of Kenya and spoke fluent Swahili. However, my Swahili language skills were lost in an attempt of acculturating into Canada. I was privileged enough to attend primary school in Kenya, where I learned the English language and by the time I arrived in Canada, I could communicate in English.

My second vivid memory as a cultural broker, was at the Jomo Kenyatta International Airport when my English language skills were put to test. As my family and I waited to board our flight to Canada with many other Somali families, a customs agent announced an update and I had to translate not only for my parents and young siblings but for others what the customs agent was saying. My role as a cultural broker created in me a sense of responsibility, to provide the assistance my family needed in integrating into Canada. As I was the only member of my family who spoke one of the official languages of our new home, I had to take a lead in translating and interpreting, a role which I still inhibit in some capacity. My bilingual ability assisted my family's settlement, as I accompany my parents to offices, shops, and hospitals to be the intermediary between them and the host nation's services. Family, as noted earlier, is the cornerstone of the Somali community, and utilizing your child as social capital is something Somali parents take pride in. As such, my identity as a Somali-Canadian was tied to my family, as Somalis are group-oriented, and I depended on my family as they depended on me. My role as cultural broker, although not unique, was very important for the development 
of my identity. Although, as a child, at times I was frustrated for being viewed as a leader, however, reflecting back, it has formed who I am as an adult.

Additionally, as with the literature review on biculturalism, my identity was formed through my ability to navigate between two languages and cultures, and my identity as SomaliCanadian, although problematized in the mainstream society is hyphenated. In the sense that I am Somali and Canadian, and both identities coexist and complement each other. Insofar as, my identity is formed by "the idea of doubleness, something that is more open, that is less exclusive and more socially inclusive" (Bayeh, 2010, p. 126), and the command of two languages and cultures plays a huge part of the development of the doubleness of my identity. Standing up and acting as a voice that can be utilized by my family to integrate, has shown me the power that language has in the sense of belonging. My experiences as a cultural broker have been an important part of my development and my family's sense of belonging.

\subsection{Sample - Participants:}

\begin{tabular}{|l|l|l|l|l|}
\hline Name & Age & Arrival age & Brokering Age & Country of birth \\
\hline Maimuna & 29 & 14 & 10 & Somalia \\
\hline Zainab & 25 & 4 & 6 & Somalia \\
\hline Hibaq & 25 & N/A & N/A & Canada \\
\hline Yasmin & 22 & 6 & 12 & Ethiopia \\
\hline Hassan & 22 & 6 & 8 & Somalia \\
\hline Source-Researcher & & & & Participants - Pseudonyms \\
\hline
\end{tabular}


Participants in this study were five Somali-Canadian cultural brokers who reside in Toronto. Toronto is home to a large portion of the Somali Diasporas in Canada, making Somalis one of the largest Black communities in Toronto. Of the five Somali-Canadian cultural brokers who were interviewed, four were women whose ages ranged from 22 to 29 , and one was male, aged 22. Four of the participants were born outside of Canada, and one was born in Canada. Those participants who were born outside of Canada, as with most Somali immigrants' narrative, did not arrive in Canada directly, but through a transit country, Kenya and Ethiopia, where they migrated to when the civil war erupted in Somalia. These four participants arrived in Canada at a young age, varying from ages 3 to 14, where they were able to acculturate faster and thus act as cultural brokers for their families. The Canadian born participant, although not primarily utilized as a cultural broker for her family, however, her interview revealed that she has provided a voice for her parents when their language fluency was questioned.

This researcher recruited the participants from several sources. The first participant was recruited from a flyer that was distributed at a Somali community event, and from there a snowball sampling was utilized, where the other four participants were found. Snowball sampling as a technique "for finding research subjects ... [where] one subject gives the researcher the name of another, who in turn provides the name of the third and so on" (Atkinson \& Rowland, 2001, p. 1) was useful to this researcher as it provided access to a community that is hard to get to. Although, there is an ethical dilemma of research participants being aware of each other's involvement in the study. This researcher, however, took the appropriate steps to ensure the confidentiality of each participant of the study. As such, the 
initial participant was provided with flyers that contained information about the study and how to contact this researcher. From there the second participant was found, and the same strategy was implemented which yield the other participants. Once the participants contacted this researcher, an email was sent which contained the purposes of the study, the types of questions they might be asked, the ideal length of the interview and the fact the interview will be audio recorded. All five interviews were conducted at a location that was convenient and ensured privacy for the participants. The interview location varied, from a conference room at a local Masjid to York University Library room.

\section{4 - Procedure: Data Collection and Analysis:}

The five interviews that were conducted for this study was guided by a semi-structured interview guide, however, this researcher utilized in-depth interviewing strategy and followed up each question for further discussions and clarification. The interviews were audio recorded and transcribed verbatim. Narrative and thematic analysis methods were used to examine the participants' data. The thematic analysis as "a method for identifying, analysing, and reporting patterns (themes) within data" (Braun \& Clarke, 2006, p. 6) were used to deduce themes that have emerged through the data and to discuss the commonality of the participants lived experiences. Further, thematic analysis was utilized as a tool to “... report experiences, meanings and the reality of participants" (Braun \& Clarke, 2006, p. 9) of this study. Narrative analysis as an inquiry that is interested in "the realm of experience, where speakers lay out how they as individuals experience certain events and confer their subjective meaning onto these 
experiences" (Bamberg, 2002, p. 78), was utilized to explore the identity formation aspect of the cultural brokers.

\section{5 - Strengths and Limitations:}

One of the strengths of this study is that it will add a well-needed voice and perspective into the existing literature on language acquisition. Thus, by examining the Somali-Canadian Diaspora experience of utilizing their bilingual children as cultural brokers, the Somali-Canadian voice will be included in literature, and provide the Somali-Canadian community a place and space for their voices to be heard. The second strength of this study is that identity is a complicated area of research, as an individual's identity is impacted by various things, and one person can embody several interlocking identities. Therefore, by examining one area where identity is constructed through language acquisition, this study will add to the growing scholarly interest in identity formation.

However, a limitation of this present study is the small size of the study, which limits its generalizability. Additionally, there are more female than male voices represented in this study, as this researcher was able to recruit more females than males, who acted as cultural brokers. Although, this dynamic is aligned with language acquisition literature as it's the daughters of immigrant families who occupy the role of cultural broker. However, this could be considered a limitation, as the voices are unequal. Another possible limitation is that all the participants of this study were well-educated individuals, which could impact on how the participants viewed and responded to the inquiry of the researcher. One of the participants had a graduate degree, another was in the process of starting their graduate degree, two had their undergraduate 
degrees and one was in the midst of finishing their undergraduate degree. It will have been interesting to have participants with varying degrees of education, however, time limitations of the study did not accord the research enough time to recruit diverse individuals with differing academic backgrounds.

\section{6 - Findings and Analysis: Thematic and Narrative Analysis}

This research project pertained to the Somali-Canadian settlement experience and focused on how children of immigrant families through their role as cultural brokers act as agents of integration. Individual qualitative interviews were conducted with five SomaliCanadian youths who had acted as cultural brokers for their families. The interviews (Appendix 10.3) were intended to collect data about the participants' experiences as cultural brokers, and how their role impacted on their families' integration and settlement experience. The questions also focused on finding whether these bilingual children's role as cultural brokers shaped their identity. The purpose of the interviews was to explore the lived experiences of the SomaliCanadian cultural brokers.

\section{1 - Demographics: Participants and Qualitative Data}

This portion of the research is intended to give context to the data collected from the interviews. The demographic information is important to understand the participants' lived experiences and perspectives informed by their role as cultural brokers. Five participants were interviewed for this research. Four of the participants were Somali-Canadian bilingual females, and one was Somali-Canadian bilingual male. Four of the participants arrived in Canada with their family as refugees, and one was born in Canada. Three of the participants were the oldest 
child of their family, one was the second oldest and one was the youngest. Four of the five participants started their brokering at a young age, and their brokering, as one of the participants described started with "calling Rogers and other companies, and maybe the bank". Therefore, this study confirms at a small scale, that bilingual children, as noted by Morales and Hanson (2005), commence their role as cultural brokers at a young age and “... they are usually the oldest child ... [and] predominantly female" (p. 491). This was echoed by one of the participants that her parents will not "bother the boys, it was me and my sister ... as we were the oldest".

All participants had at some point acted as cultural brokers, although the Canadian born participant, only stepped in as an advocate for her parents, when their language skills or rather their "Somali accents" were problematized. Through the interviews, the participants added other experiences, that are outside of the scope of this study. Multiculturalism as a policy versus as lived experiences of the mosaic of Canada was at some point on each interview problematized, although a full discussion is beyond the scope of this study, however, that data will be discussed. The five in-depth qualitative interview data were collected through one on one interviews and transcribed verbatim. A thematic analysis was done to extract themes. The thematic analysis was guided and informed by two research questions of this study, and as such, the interview dataset addressed each of the research questions. Through this process, three overall themes emerged, each with various sub-themes. As such the three major themes of this study were; the Somali refugee and settlement experience, the advocacy role that bilingual children embody, and the hyphenated identity of the cultural brokers. The subthemes 
that emerged were language acquisition of the cultural brokers, family obligation that embodied the cultural brokers' role, and the bicultural and bilingual identity of the participants, respectively.

Conversely, settlement is said to be a two-way process, where both the new settler and the host nation compromise and accommodate each other. However, "immigration and settlement is a deeply social and cultural experiences ... where notions of identity and community" (Bauder, 2012, p. 129) are multifaceted and as such new settlers find themselves facing challenges to integration. One such area is language, as new settlers might be arriving without a full grasp of either of official languages of the host nation. As the findings of this study will show, Somali bilingual youths act as social capital for their parents since their acculturation process in the host nation is quicker.

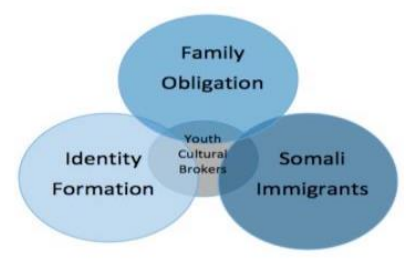

\section{2 - The Somali Refugee and Settlement Experience:}

This theme encapsulates the participants' view on the Somali Diaspora experience in Canada and transit countries. As such, the participants lived experiences as refugees in a transit country and the host nation forms their perspective of where they are and what role they embody within their families' settlement process. As remarked by Maimuna, "my appreciation of what Canada offers versus what I had in Kenya is what motivates me to act as a voice for my 
mother". Four of the five participants went through the grueling process of fleeing from one nation to another, and in the process, being "caught between danger at home and loss of identity in a strange land" (Stein, 1980, p. 1). Insofar as, refugees, whether in the transit countries or the host nation, have a sense of marginalization, as noted by Maimuna "coming into a new country [Kenya and Canada] and being far away from my culture that I was familiar with", she felt lost. This remark aligns with the refugee experiences in the process of "fleeing ... home ... [in an effort to] seek safety in strange societies where they may be isolated, different, and often impoverished" (Stein, 1980, p. 1). Further, Maimuna echoes this sentiment by reflecting her time in the refugee camp in Kenya, which she recalls as being "... hard, [with] no running water ... [and] no formal education".

For the four participants that came with their families as refugees in Canada, they often contrasted their experiences of being in the transit country and the host nation, which made their role as a cultural broker a positive experience. Yasmin asserts that "Canada is about appreciating and remembering that I was not always a Canadian, there are problems here as well, but you can appreciate what you got and while still questioning the inconsistency within the Canadian narrative". Moreover, the cultural brokers who came with their families as refugees, give credit to parents for their survival, and are happy to assist in the integration of their families, since they acculturated faster. As Yasmin notes, "I could not have done half of the things my parents did for us to get here [Canada] ... but in terms of the integration part ... that was something I was able to assist with", which both Maimuna and Hassan concurred with through their interview. Maimuna states that "the integration from the Somali perspective, you 
have the responsibility to help your family to integrate", and Hassan echoed this sentiment by stating that "it was a unique integration process ... [as] the kids learned first and helped the parents integrate".

Furthermore, as the study done by Hua and Costigan (2011) stated, immigrant children, have a strong sense of attachment to their parents, mainly because of the "collectivistic orientations" (p.896) of such families. However, this researcher, through the participants' interviews as well as the researcher's personal narrative, can assert that the refugee process itself necessitates families to be reliant on each other to survive their circumstances. As such, the bilingual children of Somali parents, tend to avail themselves without coercion to alleviate the refugee struggles and the barriers that come with being in a host nation. Throughout the research and the interviews process, language was indicated as being one of the biggest barriers to integration. Essentially, since "language is a central component of the integration of immigrants into their host societies" (Esser, 2006, p. 7), the lack of such languages can be a barrier to integration. Thus, "immigrants with 'non-official' languages basically face .... problems in Canada" (Esser, 2006, p. 6) and these problems or barriers are mitigated by the bilingual children of immigrant families.

As one participant, states

"Collectively within the family, the whole family is navigating the integration process and the child is learning along with the parents ... [but] the child acculturates faster and has to act as a cultural broker for the family".

Which Zainab concurs with, by stating "being a newcomer, my mother depended on my developing language skills, which eased the integration process". Cultural brokers through their 
role as agents of integration can diminish the stresses of migration, by utilizing their developing language skills. Although at first, the bilingual child's role is limited to the day to day interaction within the Canadian society, as remarked by Zainab, however, as the bilingual child matures their responsibilities intensify. Four of the participants' interviews reveal that as the bilingual child matures, their role develops with them.

\section{3 - Acculturation: Language acquisition of the Somali-Canadian youth}

The acculturation theory as a well-developed area of study relates to, as Gibson (2001) notes, the changes that take place because of contact between two divergent groups, with different cultures and social influences. However, the acculturation theory has been problematized through a critical theory lens, because it has "... omitted to critically examine acculturation in relation to dominant-subordinate oppression, mutual transformation of immigrants and the receiving society, formulation and reformulation of identities and issues of social justice" (Ngo, 2008, p. 2). Although, in this study, some of those issues are discussed through the participants' reflections of their identities through their language acquisition, however, a full discussion of the critical theory lens is beyond the scope of this paper. The acculturation theory is utilized here, as a theory that examines the changes that occur when new immigrants arrive in a host nation. As such, four of the five participants credited their acculturation process as the determinant factor that has worked to their advantage, as they gained new knowledge and language, they could utilize their new skills in the betterment of their families. As such, under the theme of Somali Diaspora experience in Canada and abroad, the cultural brokers in this study discussed the fact that they were able to acculturate faster, 
due to schooling and socialization, which made the integration process for their families that much easier. As Maimuna remarked;

"During my time in a refugee camp in Kenya, I picked the language and culture of the transit country, and I was able to help my mother navigate the camp and its officials. I went with her to interviews, as well as doctor appointments, and acted as an intermediary".

Maimuna's role as a cultural broker for her mother continued when they arrived in Canada, as she notes;

"My role as a cultural broker, although more complicated due to my mother's developing medical conditions, it was also easier as I had the stability of education and home ... and as I learned something, I was able to explain and contextualize to my mother what was going on".

The literature on language acquisition has shown that family members acculturate to the new host nation's language and culture at a different pace, and as such, the members of the immigrant family who acculturates faster is utilized as social capital and to navigate the new land. Furthermore, as "the optimal acculturation strategy for immigrants is integration ... which appears to be a consistent predictor of more positive outcome" (Bhatia S., 2002, p. 58) for the new settler in the host nation. Therefore, to effectively function in the host nation, Somali parents, utilize their children as assets of integration, and to navigate the new space they have settled. Zainab in discussing her acculturation process remarked;

"As my language skills were developing, I was able to recognize the need my family had for my new skill, and I was able to help my mother, in particular, deal with the new society in running the day-to-day activities for the family". 
Although Zainab began her cultural brokering at a young age, she stated that "it was not stressful ... as it always helped me get better at English. Through my brokering, I was able to develop a better knowledge of the English language and the Canadian culture".

One fascinating thread of the four cultural brokers who arrived with the families as refugees is that they lacked either of Canada's official language, however, as they were enrolled in schools, they were able to grasp the language rather quickly. As the literature on language acquisition has shown that children in immigrant families, learn and thus acculturate faster. Moreover, the interviews revealed that, as they were going through the process of learning the new language themselves, there was an implicit understanding that as they learned, they will assist their families as much as they could. Yasmin in discussing her acculturation process notes; "I have always been good with language. My family's journey to Canada begins with us fleeing the war and seeking shelter in Ethiopia and Libya, before we arrived in Canada, and I was able to pick up the languages of both countries and when we came to Canada, my ESL teachers were impressed with my ability to acculturate and learn the new language".

Furthermore, a related concept to the acculturation process and that is relevant to the participants of this study is the enculturation process. Enculturation "generally refers to the process by which individuals learn and adopt the ways and manners of their respective culture ... which immigrant parents are keen that their children should retain" (Smokowski, Rose, \& Bacallao, 2008). As such, the Somali-Canadian youths in this study, are able to acculturate and enculturate, as Hassan notes;

"Since I left Somali when I was a baby, I learn my heritage from my parents, at the same time I am learning the Canadian culture. I am able to retain both cultures simultaneously and I think it makes me a better cultural broker, as I am able to contextualize the difference to my parents". 
Yasmin in agreement with Hassan's point stated that

"The fact that I am able to acculturate and maintain my heritage, makes my role as cultural broker an effective one. I am able to be my parent's voice and navigate their settlement and integration with them".

\section{4 - Cultural Brokers' role as Advocates:}

Cultural brokering "takes place along a continuum from answering the household phone to reading labels at the grocery store" (Fisher, 2010, p. 13) to more complicated aspects of integrating, including advocating for the family. Valenzuela's (1999) study on Gender Roles and Settlement Activities Among Children and Their Immigrant Families, reports that the advocacy role that cultural brokers embody is a substantial role that makes a difference in their families' settlement experience. Specifically, the bilingual child's advocacy role is "... in which children intervene, mediate, or advocate on behalf of their parents or households during difficult financial, legal or other complicated transactions or situations" (p.727). This theme, thus, captures the participants' role in their families as ambassadors who use their voice to advocate for their family in interacting with societal agents in the host nation. Yasmin's experience as a cultural broker encapsulates the role of a bilingual child, as she states'

"As I got older is when I began to understand that my parents are going to be relying on me for what I just learned ... that was something I was able to assist with. My role as a cultural broker was at first mainly about the small stuff, but my role gradually increased to dealing with more complicated aspects of life ... including dealing with the criminal justice system, and dealing with lawyers, and authority figures. When I was younger my parents relied on me for the day to day of translating and navigating the new language and culture, however, as I got older, my parents were able to rely on me for the more challenging tasks". 
Additionally, as Valenzuela notes, cultural brokers in their role as agents of integration have to "... confront rude salesperson, school officials, bankers, or other important people who show little patience toward their parents or siblings"(p.727). All the participants, including this researcher, had to at some point step in and be the advocate voice for their families. Hibaq succinctly notes that she utilizes her advocate voice when her "parents' accent act as a barrier ... [as such] they ask me to accompany them for certain things". As a cultural broker for my family, I had instances where I had to step in and confront or silence individuals who were clearly utilizing their position of power to intimidate and be condescending, to protect my parent's agency. Maimuna in discussing her advocate role concurs with this sentiment and states that;

"It comes with the territory of being a cultural broker ... advocating for them is the hallmark of my role. Taking my mother anywhere ... I have the responsibility of advocating for my mother. Although, sometimes I feel like I get resistance from authority figures, and I have to act like a lawyer and explain what is happening ... I put on my advocate role hat and step in when I feel like my mother's agency is being threatened".

Cultural broker's advocacy role relates directly to the immigrant parent's language ability and the host nation's agents' inability to communicate or in some instances reject to communicate, which "prompts intervention"(Valenzuela, 2010, p.727) from cultural brokers. Further, cultural brokers' advocacy role impacts on "... systemic discrimination in the wider [host nation] community... [that] puts the onus on the family to become more like us ... and marginalize ... foreign language[s]" (Fisher, 2010, p. 14). Cultural brokers, thus, are there to utilize their bilingualism to advocate on behalf of their parents.

As Yasmin in discussing her advocate role for her parent states; 
"I had to advocate for them because they were afraid of losing whatever status they had ... if they complain about their treatment ... whether it was a social agency or banks, so we [cultural]brokers stand up for them and advocate for their rights. My parents relied on me to be their voice and [as such] 60\% of my brokering was for advocating for them".

Bilingual children, as Zainab, states "stand up and protect their parents from unruly people ... I

can clearly remember being 10-years-old and stopping an adult from verbally abusing my

mother because she lacked the language skills". Hassan, in concurrence with Zainab's point, adds that "there have been numerous occasions where I had to fight and stand up for my parents, because of the frustration that they are not listening to them". Cultural brokers, in their role as advocates for the parents, develop a strong sense of self-efficacy, insofar as, "developing a strong sense of personal empowerment as a result of their diverse brokering experiences", which manifest into cultural brokers "... competently advocating for their parents" (Buriel, 1998, p. 285). Through their role as intermediaries, cultural brokers become a strategic tool that can be dispensed to

"access to information only found in the dominant language and mainstream institutions and to communicate with English monolingual speakers in order to acquire ... services not available in the ethnic communities ... [as such] immigrant children mediators serve as important source of information and interpretation for linguistic minorities " (Chu, 1999, p. 92)

\section{5 - Familism: Family Obligation}

Familism as a concept that reflects the "... core construct of ... familial obligation" (Wu \& Kim, 2009, p. 705) in the immigrant families is displayed through the interviews of the cultural brokers in this study. Wu and Kim (2009) study on Chinese American Adolescents' perception of their cultural brokering, stated that family obligation plays a big part and "propels adolescents 
... to believe in the importance of assisting the family" (p.705) in the integration process.

Although their study focused on the Chinese American experience of utilizing their children as assets and the cultural brokers' positive outlook of their involvement in their families' settlement, the participants of this study highlighted similar sentiment of family obligation. Family obligation, however, was not viewed in a negative light in this study, as the participants' construction of what family is in the Somali Diaspora influences their perception of their role as cultural brokers. Moreover, family obligation was juxtaposed to advocacy by the participants in this study. All the participants believed that it was under their purview to stand up for their parents when they were being alienated. Specifically, Hibaq notes that "integration is made harder for my parents, because they felt isolated and not accepted, because of their language skills". In the same vein, Zainab stated that;

"Although there are multitudes of services that newcomers can use to assist them to settle into the host nation, such as faith organizations or community services, however, when it came to the day-to-day advocating, it was part of my family obligation to stand up for my parents and protest their mistreatment".

Yasmin, in discussing why her role as an advocate is an important aspect of her cultural brokering states that;

"They have been a change in Somali community liaison ... Somali immigrants use to rely on such services as a resource ... but one thing that has changed is that those services were no longer being offered by the Somali community centers, and there was a transition of Somali parents relying on community centers to relying on their children as cultural brokers and advocates".

There has been a clear direction from the government that devalues community centers and thus cuts or reduces funding for certain ethno-community centers as reported by OCASI (2015, p.5). As such, not all communities have access to services that will elevate their integration into 
society, and make their migration process easier. Essentially, making cultural brokers' role an important aspect of settlement. Therefore, children in immigrant families through their role as ambassadors, develop skills that assist their families in integrating and settling in Canada.

Additionally, Hassan in discussing his advocacy role adds;

"Yes, I had to step in and be an advocate, when my parents were clearly being mistreated or disrespected ... the way 'they' talk down to you, there is a superiority aspect to it. You can ask them to repeat what you do not understand, there is no need to be disrespectful. I feel people always make assumptions about the lack of language and just assume that you must not speak English just because of your ethnicity".

Furthermore, all participants shared stresses of being a cultural broker, in terms of dealing with the Canadian society, whether it is school officials or government agents, Yasmin stated it succinctly that;

"They choose to hear our voices when they want and not hear our voices when they do not want to hear us ... essentially, they choose when it is convenient for them. I am still being undermined as the voice of my parents, and that is just vexing".

Part of the problem is the social construction of the child, as such cultural brokers have to deal with "... people who feel that it is not appropriate for a child to act as a cultural broker" (Fisher, 2010, p. 14), and as such assume that “... the family is placing an unfair burden on its children" (Fisher, 2010, p. 14). However, all the participants of this current study have reported how proud they are to be supporting their families through the settlement process. As Hibaq stated, "my parents are very strong people and they can take care of themselves, however, having me there just in case, makes all the difference, and as their child, that makes me proud to support them". Hibaq's parents arrived in Canada before she was born, however, she finds herself acting as an advocate for them, although, with less frequency than the other participants. 
Zainab had similar thoughts, being a cultural broker for her mother made her feel proud of her ability to aid her mother and circumvent any difficulties she might experience. She states;

"My mother is a strong and a capable woman, who got us out of a war zone, and who taught me the English alphabets, but now, she feels powerless, and alienated, because her language skills are questioned. Although she is capable, she feels more comfortable when I am with her ... and that makes me feel proud in a small way I can be there for my mother and help her integrate into the new culture, by interpreting the culture for her".

The essential point here is that the Somali-Canadian cultural brokers represented in this study, are clearly aware of the importance of their role, and their role as bilingual children, in turn, influences the formation of their identity. Cultural brokers' "... involvement in both cultures marks [their] integration ... [and] biculturalism" (Smokowski, Rose, \& Bacallao, 2008, p. 295) identity. Biculturalism as a concept examines the duality of immigrants, who embody two unique and at times separate identities in one body.

\section{6 - Hyphenated Identity: Biculturalism}

In discussing the cultural brokers' identity, and whether their identity has been influenced by their language acquisition, and thus their bilingualism, the idea of hyphened identities emerged as a theme through the interviews. Cultural brokers' as translators of language "... creates interactional and interpersonal spaces where knowledge is shared and identities get formed and negotiated" (Lee, Hill-Bonnet, \& Raley, 2011, p. 323). Through their role as social capital, the cultural brokers' in this study create a space where their gained knowledge is transferred to and utilized by the parents. All the participants in this study reported that their ability to navigate between two different languages and cultures has had an influence on how their identity formed. Insofar as "language is a critical element of ... identity 
and a fundamental component of acculturation" (Nguyen \& Ahmadpanah, 2014, p. 1216), thus acculturating and being the voice for their parents, cultural brokers' identity is hyphenated. In the sense that they are both Somali and Canadian, without valuing one over the other.

Although, as remarked by Hassan, their bodies are problematized in the mainstream society, since they are Black and Muslim. Hassan further states that;

"My identity is indeed influenced by my ability to navigate between two different spaces, in terms of language and culture. As a racialized individual, and from the perspective of a Muslim black male, my identity at times are problematized, and things are attached to my body that has nothing to do with me. However, as individual who embodies two different identities, I tend to take the good and leave the bad from both of my identities. There are things, that are primarily Somali and Canadian that I admire and emulate and there are things that I just do not follow, so I pick and choose what fits into my identity, and as such my identity is hyphenated".

Hassan's outlook on his identity fits into the conceptualization of a hyphened identity.

Insofar as "a hyphenated ... identity ... contains a great deal of flexibility within the hyphenated identity itself. [Since] it ... represents a step away from a purely country of origin identity" (Renshon, 2011, p. 1). Additionally, the cultural broker as a “... bicultural individual selects aspects from the heritage and receiving cultures and integrates them into an individualized 'culture' that is not directly reducible to either the heritage or receiving cultural streams" (Schwartz \& Unger, 2010, p. 27). All the participants of this current study have remarked that their identity is bicultural, and as such, they identify with both their Somali-ness and Canadianness. Thus, the bicultural individual is influenced and impacted by both of their embodied identities, and as such their hyphened identity reflects their worldview. Issues of "race and gender are crucial signifiers that mark our locations and positions in the center or margins" (Bhatia \& Ram, 2001, p. 7) and as Hassan remarked, identities can be problematized based on 
the marginal position the mainstream society assigns certain bodies. However, biculturalism

does not, as noted by Shwartz and Unger (2010), develop in a vacuum, but

"rather, it is likely a product of cultural and contextual forces that steer young people toward some cultural options and away from others. These forces are not constant, but rather change over time, vary across local and national contexts, and may operate differently depending on the immigrant group and receiving society in question". (p. 30)

Therefore, identity is always developing based on the experiences of the individuals.

Maimuna adds that;

"Sometimes I find myself muted because I have nothing to say about the identity that I am boxed in as if I am only one thing or appear to be one thing ... my Canadian identity at times is questioned, they automatically look at my face and say that I must be something else ... being Canadian is ascribed to something particular that I must not fit into. I see myself as much as Canadian as Somali, but my Canadian-ness is always questioned. I grew up here, as such I understand the culture and language, and I can help my mother navigate the society. But my identity and where I belong is challenged".

Hassan adds;

"Although sometimes I feel there is a sense of social exclusion, where I am neither Somali or Canadian enough and excluded from both groups equally ... however, those are the moments where my bilingualism comes handy, and I appreciate how important it is to my ability to function and be a good cultural broker. When my identity is challenged, I remember and realize the benefits of having two identities and navigating between them as a tool to fight marginalization from either side. Although, mostly it's my Canadian identity that gets challenged".

Somali-Canadian youths have to often negotiate their identities within the mainstream society,

that has always problematized certain bodies. Yasmin asserts that;

"Although my identity is at times questioned, I can deal with that and articulate my feelings. It is a different story with my parents, who feel they are being differentiated, but cannot articulate what they want to say, and that is why my role as a cultural broker is important. My identity, I know, I am both Somali and Canadian, although others might want to say something else". 
The cultural brokers in this study, although frustrated that their Canadian identity is questioned, consider their identities as a hyphen, and as such acknowledge their duality.

Further, in the Diasporic context "hyphenated identity is a critical element in the process of ... acquisition" (Renshon, 2011, p. 2) and it involves “... some back and forth movement (Renshon, 2011, p. 2)". As Zainab stated;

"My hyphened identity is indeed flexible based on the situation that I am in, and that is one thing I love about hyphened identities, as we can occupy more than one identity and thus, fight back from being boxed into one".

Hibaq, in turn, stated that;

"Her duality or hyphened identity has served her well since she can function pretty well in both identities or worlds ... and although I was born in Canada, I embody both, my birth country and my ethnic background, identities".

Cultural brokers embodying a hyphened identity in a multicultural context represents what integration "implies ... the preservation of home culture and an active involvement in the host culture" (Bhatia \& Ram, 2001, p. 4). As such, the participants in this study were able to maintain two identities, and although at times contradictory, they utilize their hyphen identity as an integrative tool for their families. Yasmin in discussing her duality stated that'

"My identity formation, if I think about it, is actually about my ability to communicate and understand two varying languages and cultures, and I am able to understand the culture because of my bilingual skills. Language has formed my identity, I think language and identity are interconnected, especially in the Somali Diaspora".

The participants in this study as "... linguistic minority who grew up exposed to their home language and the majority language" (Park, 2013, p. 31)tend to blend the cultures that are associated with both languages. As Hassan stated, language and culture are intermingled; 
"You cannot separate language and identity, language impacts on your identity. It impacts who you identify with and the identity formation process. Language informs your identity".

Hassan continues to state that;

"In any given situation, I will have to switch who I am at that time given the circumstances ... alternatively, there are instances where I feel comfortable that my identities are not exclusive and reliant on each other, where I can champion both and feel welcome and accepted ... this is usually the moments where I sense my multiculturalism".

\section{7 - Multiculturalism - Identity Discourse}

Multiculturalism as a discourse emerged as a subcategory in discussing cultural brokers' identity formation. Although, a comprehensive discussion of the Multiculturalism policy is beyond the scope of this paper, however, a quick discussion is warranted. While reflecting on what has impacted and influenced their identity, and the difficulties of their problematized bodies, the participants remarked that Canada's Multiculturalism policy has not fully been realized as it was intended. Although, all participants credited Canada's Multiculturalism as a machinery of inclusivity, however, they criticized it for the lack of implementing the policy itself. Additionally, Multiculturalism as a discourse has been criticized from several angles, as Park (2016) notes, the

"adoption of multiculturalism policies has served to obscure and conceal the continuing reality of racist assumptions among the majority of Canadians ... and the continuous racial and systematic discrimination against minorities in Canada, characterized by intolerance against minorities' culture, language and race" (p. 32).

Yasmin in accord with Park's conceptualization of Multiculturalism stated that;

"I think it is lip service, but also it could be something real, but it is not right now ... it is there but it is not being used the way it was intended to be used. Politicians play on the 
fact that we are multicultural ... we sell Canada as multicultural but the meaning is conflated ... which is scary because we are hiding so many things about inequality and racialization ${ }^{4}$. It is a discursive tool that the government uses ... which essentially silences different voices, because we can argue that we have no racial problem in Canada because we are multicultural".

Therefore, the contradictory nature of the Canadian discourse on integration and Multiculturalism that on the one hand welcomes difference and accepts plurality and on the other hand expects immigrants, as noted by Li (2003), to conform and "to accept prevailing values and beliefs and to acquire ... behavioural patterns similar to majority of Canadians" (p.318), was seen as oppositional. Additionally, in Hibaq's interview, she stated that;

"The government does not embrace the full multicultural policy in place ... lived experiences are different, as the mosaic of Canada is multicultural, in terms of having many different faces, and thus many different communities and that is positive. But the actual policy as it was crafted has not been implemented".

Therefore, Multiculturalism as the unrealized policy was criticized, although, all the participants did acknowledge that without Multiculturalism, whether it is fully realized or not, they will not be in Canada. As the Canadian state, before the implementation of the point system and the Multiculturalism policy restricted certain nationalities as immigrants and refugees. The Somali-Canadian child, thus, in their role as cultural brokers, utilize their bilingualism and biculturalism to better serve their parents as conduits of integration, and to convey the dissonance that exists between acceptance and racialization. In terms of contextualizing the realities of Multiculturalism, and the mosaic of Canada.

\footnotetext{
${ }^{4}$ Racialization is employed in this paper to refer to the "process that assumes that race is the primary, natural, and neutral means of categorization, and that groups are distinct also in behavioural characteristics" (Tang \& Browne, 2008, p. 114) ... Racialization also refers to the "process by which those in power construct the social identity of others by attaching meaning to their bodily markers ..." (Smith, 2007, p. 243)
} 


\section{7 - Discussion and Conclusion}

The goal of this present study was to better understand the role of children in immigrant families play in the integration and settlement process of their families through their language acquisition. Additionally, a second component of the study was to examine how bilingual children's role as cultural brokers, influenced their identity formation. As such, this study aimed to answer two research questions:

\section{In what ways do cultural brokers play a role as ambassadors of language and culture to assist their families in navigating the challenges of a new country? \\ 2. In what ways do the cultural brokers' bilingual abilities inform their identity?}

The findings of this research revealed several interlocking areas related to bilingual children of Somali immigrant parents, including the cultural brokers' view on the Somali Diaspora experience, and how that influences their role as cultural brokers, how their advocacy role impacts on their families' integration and settlement process, as well as how it reinforces their self-efficacy, and how their bilingualism influences their identity. These findings foster a better understanding of the Somali Diaspora experience of utilizing their bilingual children as assets in the host nation. It also adds a well-needed voice of the Somali Diaspora in the language acquisition literature. Furthermore, the findings of this research study coincide with the review of the literature on language acquisition, including the development of biculturalism identity of the cultural brokers.

The notion that immigrant families utilize their children as assets of integration, as reported by Reynolds and Orellana (2009), Tse (1999), Valenzuela (1999) and other social scientists, was evident in this study. Further, "from a monolingual immigrant parent's 
perspective, the use of family member to provide translation ..." (Reynolds \& Orellana, 2009, p. 213) and interpretation services "when not rendered by institutions is a strategic response [and] an assertion of a competent self" (Reynolds \& Orellana, 2009, p. 213). As such, the Somali immigrant's utilization of their bilingual children as cultural brokers restores a certain degree of empowerment. Insofar as their children as cultural brokers are navigating their integration and settlement process.

Through the interviews, although the participants' views of their role as cultural brokers were viewed in a positive light, however, the participants did acknowledge that in their younger days there was a sense of frustration that accompanied their role. As such, the process of Adultification, Parentification and Role Reversal that are evident in the research manifested through the participants' narratives. The participants, hence, reported sentiments of growing up too fast, feeling responsible for their parents and essentially occupying a role that they should not occupy at a young age. However, all the participant did identify these sentiments as temporary as the nature of their role become more intertwined with daily routines, and accepted as the norm in their families. Further, the participants reported through their interviews that they utilized 'Para-Phrasing' as a tool of contextualizing for parents, and not paraphrasing what was being said. The participants, thus, translated to their parents directly and did not change the meaning of whatever was being said. The acculturation and enculturation theory was an important influence on the Somali-Canadian child's development of their bicultural identity, as all the participants identify both as Somali and Canadian, and form their own their identity through their Somali-ness and Canadian-ness. 
The findings of this study suggest that, in regard to the first question, that the SomaliCanadian child does play a role in the integration and settlement process of their parents, and families in general. Further, unlike earlier studies that problematized the role of children in immigrant families as cultural brokers, the participants of this study viewed their role as a cultural broker positively. The society that demands their involvement in the process was, on the other hand, was viewed negatively. In regard to the second question, interestingly, the participants credited their involvement as cultural brokers as a character building role and appreciated their bilingualism. The ability to navigate within two distinct languages and cultures was viewed positively and noted as being a unique aspect of their lives.

\section{8 - Recommendation - Further Studies}

As this study was limited to its parameters of examining language acquisition as it relates to cultural brokers' identity, as a researcher I was not able to further examine how these identities are impacted within a Multicultural state that still inhibits colonial tactics of racializing and creating categories of people to 'other'. Although, Multiculturalism was raised and discussed through the participants' voices, however, it will have been interesting if the focus was on Multiculturalism and identity. As I have goals of continuing my education and obtaining my PhD., I plan to further examine how identities are constructed, reconstructed and deconstructed in a society that purports to be equal, but practices inequality. As such, a recommendation for further study will be a focus on how the racialized Multicultural body embodies divergent identities, and how those identities are impacted and influenced by their peripheral position in society. 
In terms of language and identity, a potential area of interest will be to examine how colonial tactics of whiteness and white supremacy has manifested itself in a multicultural society, and how that impacts on the identity of the mosaic of Canada. On the other hand, it will be interesting to examine several communities with similar trajectories of migrating to Canada, and how each community utilizes cultural brokers to integrate and settle into Canada, as a host nation. Although this type study was not ideal for this researcher, as there were time constraints, however, it will be interesting to do compare and contrast analysis of several immigrant communities. 


\section{Appendices}

\section{A.1 - Constant Form}

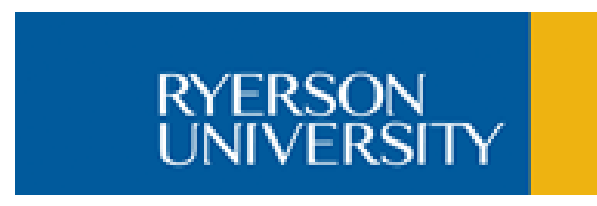

Ryerson University

Consent Agreement

You are being invited to participate in a research study. Please read this consent form so that you understand what your participation will involve. Before you consent to participate, please ask any questions to be sure you understand what your participation will involve.

\section{Ambassadors of Language and Culture:}

The role children of immigrant families play in the integration process of their families as translators and interpreters of language and culture

INVESTIGATORS: This research study is being conducted by:

Abdinasir Farah Mohamud MA(c) Immigration and Settlement Studies, Ryerson University

$\checkmark \quad$ I am a graduate student and this research is being done in partial fulfillment of my graduate degree (Immigration and Settlement Studies), and the research is being done under the direct supervision of Dr. Francis Hare.

Dr. Francis Hare, Professor Emeritus, School of Child and Youth Care, Ryerson University

If you have any questions or concerns about the research, please feel free to contact:

Abdinasir Farah Mohamud

a3mohamu@ryerson.ca

Dr. Francis Hare

School of Child and Youth Care, 


\section{Professor Emeritus}

Ryerson University

350 Victoria Street

Toronto, Ontario,

M5B 2K3

francis.hare@ryerson.ca

416-979-5000 ext 6200

\section{PURPOSE OF THE STUDY:}

The objective of this study is to explore the role of children of Somali immigrants as interpreters and translators of language and culture and investigate how these roles impact the family's integration and settlement experience. The focus of this research will be on the process through which the Somalia-Canadian community utilizes their children as ambassadors of language and culture. This topic was selected primarily because there has been very little research on this community. The study aims explore whether their role as ambassadors of language and culture has an impact on the family dynamics, and what effects it has on the child or children specifically. In this study, there will be 5-6 cultural brokers, who will be interviewed, and 2025 immigrant parents, who will be surveyed. The eligibility criteria for identifying prospective participants is that the interviewee must have at some point in their childhood acted as a cultural broker for their families, and the survey participants, they must have used their children as cultural brokers. The results of this study will contribute to my Major Research Project, as a partial completion of my Immigration and Settlement Studies (M.A). The completed project might be presented at conferences and/or might be published in a journal article.

For this study, these terms refer to:

Bilingual children: The concept of 'bilingual children' will refer to the command of two cultures and languages that the children of immigrant families hold.

Cultural Brokers: The term 'cultural brokers' will be used to refer to Somali-immigrant children's ability to navigate and negotiate between two cultures and languages in assisting their family's settlement and integration process.

\section{WHATPARTICIPATION MEANS:}

If you volunteer to participate in this study, you will be asked to participate in a one-on-one interview.

Interview format

- Interviews will last 1-2 hours.

- Interviews will be conducted at a time of your choosing. 
- The interviews will be held at a location that is convenient and safe for the participants. To protect the participants' privacy the location will be an enclosed room where there will be visual privacy. The physical location of the interview will be either a library room at Ryerson University or a private room in a community center.

- You will be provided with all necessary information prior to the interview, including the consent form, and possible interview questions.

- You are free to end the interview at any time and to choose not to answer questions.

Type of Information Sought

- Subject to your consent, I will collect some personal information, including your name, age, phone number and email address.

- Your identity will be protected and kept confidential throughout the study. Your phone number will be collected to contact you for interviewing purposes and your e-mail address will be collected so that a written transcript of your interview can be returned to you for review.

- The written transcript will be made available to you within 2 weeks of the interview and you will have 10 days to provide your feedback, request changes, or withdraw your information or data from the study.

- Your identity will not be included in the dissemination of the results of the research.

- This study is primarily interested in your experience as a cultural broker.

Retention and Dissemination of Information

- With the permission of the interviewee, the data collected will be retained for 5 years. The rationale for this length of time is to further develop this study and to build on it through my potential $\mathrm{PhD}$ dissertation.

- With the permission of the interviewee, the interview will be audio recorded.

- I will make the written transcripts of the interviews available, after which the audio recordings will be deleted.

- All participants will be provided with access to the transcriptions, which they may review and revise.

- Transcripts will be destroyed after the completion of the study.

- All research findings and publications will be made available to participants upon their request.

\section{POTENTIAL BENEFITS:}

Participants may not benefit directly from the study, however information gathered from the study may contribute to literature by examining the Somali-Canadian immigrant experience of utilizing their bilingual children as cultural brokers. As well as providing the Somali community a place and space for their voices to be added to the existing literature.

\section{WHAT ARE THE POTENTIAL RISKS TO YOU AS A PARTICIPANT:}


The risks associated with participation are very low. Participants may experience discomfort and feel uncomfortable while being asked to reflect on their past experiences playing the role of interpreter and translator for their families. To mitigate this risk, the participant will be given the option of skipping questions or not answering any questions that makes them uncomfortable, as well as, providing information on counseling services in their area. There is a low risk of personal identity being revealed, and to mitigate this further, the participant has control over the location and time of the interviewing. You have control over choosing where, when and how long the interview will last.

\section{CONFIDENTIALITY:}

I will be collecting some personal information, including your name, age, phone number and email address. However, I will protect your identity and maintain the confidentiality of this information. Your personal information will not be associated with the data collected, as pseudonyms will be used. Data will be stored separately, in different password protected files, from any identifying information.

There will be audio recordings of the interviews, which will be destroyed once transcribed. You will be given the transcripts to review and revise. The transcripts will be deleted and hard copies shredded after completion of the study. Information will not be distributed electronically. All participants will be provided with access to the transcripts and the study results will be made available to participants.

\section{INCENTIVES FOR PARTICIPATION:}

You will not be given any incentives for participation in this study.

\section{VOLUNTARY PARTICIPATION AND WITHDRAWAL:}

The participation of this study is voluntary, as such, you have the control to be in this study. Throughout the interviewing process, you have the option of skipping questions that make you uncomfortable, as well as, stopping the interview. You may withdraw from the study at any time. If you choose to stop participating, you may also choose to not have your data included in the study. Within two weeks of your interview, the written transcript will be made available to you for your revision. You will have 10 days once you receive a copy of your transcribed interview to decide if you want to withdraw from participating. Withdrawing within this period will result in the removal and destruction of your data. Your choice of whether to participate will not influence your future relations with Ryerson University or the investigators, Abdinasir Farah Mohamud and Dr. Francis Hare, involved in the research.

QUESTIONS ABOUT THE STUDY: If you have any questions about this research, please ask. If you have questions later about the research, you may contact:

Abdinasir Farah Mohamud

a3mohamu@ryerson.ca 
Dr. Francis Hare

Child and Youth Care Department,

Professor Emeritus

Ryerson University

350 Victoria Street

Toronto, Ontario,

M5B 2K3

francis.hare@,ryerson.ca

416-979-5000 ext 6200

This study has been reviewed by the Ryerson University Research Ethics Board. If you have questions regarding your rights as a participant in this study please contact:

Research Ethics Board

c/o Office of the Vice President, Research and Innovation

Ryerson University

350 Victoria Street

Toronto, ON M5B 2K3

416-979-5042

rebchair@,ryerson.ca

\section{AN EXPLORATORY STUDY OF POLICE SERVICE POLICIES AND PRACTICES SURROUNDING UNDOCUMENTED/NON-STATUS INDIVIDUALS}

\section{CONFIRMATION OF AGREEMENT:}

Your signature below indicates that you have read the information in this agreement and have had a chance to ask any questions you have about the study. Your signature also indicates that you agree to participate in the study and have been told that you can change your mind and withdraw your consent to participate at any time. You have been given a copy of this agreement.

You have been told that by signing this consent agreement you are not giving up any of your legal rights. 
Name of Participant (please print)

Signature of Participant

Date

I agree to be audio-recorded for the purposes of this study. I understand how these recordings will be stored and destroyed.

Signature of Participant

Date 
RYERSON

UNIVERSITY

\section{PARTICIPANTS NEEDED FOR RESEARCH ON: AMBASSADORS OF LANGUAGE AND CULTURE:}

\section{THE ROLE CHILDREN OF IMMIGRANT FAMILIES PLAY IN THE INTEGRATION PROCESS OF THEIR FAMILIES AS TRANSLATORS AND INTERPRETERS OF LANGUAGE AND CULTURE}

\section{Have You:}

1. As a child acted in the role of translator of language for your family?

2. As a child acted in the role of interpreter of culture to your family?

Are You:

3. A bilingual Somali child who has acted as a cultural broker for your family?

4. A child of a Somali immigrant family, ages 16-25??

If you answered YES to the above noted questions you are invited to volunteer in this study of cultural brokers, focusing on the Somali immigrant experience of utilizing their children as an asset to get settled and integrated into Canada.

You will be asked to participate in a one-on-one interview in which you will be asked various aspects of your personal experience as a cultural broker. The interview will be a single session that will not take longer than 60-90 minutes.

If you are interested in participating in this study, or for more information please contact:

\section{Primary Researcher}

Abdinasir F. Mohamud, Master of Arts (MA) in Immigration and Settlement Studies. a3mohamu@ ryerson.ca

I am a graduate student and this research is being done in partial fulfillment of my graduate degree and the research is being done under the direct supervision of Dr. Francis Hare.

\section{Research Supervisor}

Dr. Francis Hare, Department Child and Youth Care

francis.hare@ryerson.ca

This research study has been reviewed and approved by the Ryerson University Research Ethics Board. 


\section{A.3 - Interview Questions}

These questions were used as guide ...

1. What is your name?

2. How old are you?

3. Where were, you born? Canada or migrated to Canada?

4. If you migrant, how old were you when you settled in Canada?

5. Did your family arrive directly from Somali, or were they in transit somewhere else?

6. Did speak English when you arrived?

7. If so, did you acculturate the culture and language of the transit country?

8. How old were you when you first started cultural brokering?

9. How did it make you feel? (I know you might not feel comfortable with answering this question, but please do your best to answer it.)

10. What do you think is the role of a child in the integration and settlement of their family?

11. Do you think language and identity are interlocked or interrelated ...?

12. Do you think your role as cultural broker helped your family to integrate easily into Canada?

13. Do you still perform that role?

14. How often do you translate and interpret for your family?

15. Has your role as a cultural broker affected your relationship with your parents/family?

16. Was there a moment you remember that made you proud to be a cultural broker?

17. Has it hindered you in any way? Can you please give examples if you feel comfortable enough?

18. Has your duality, in the sense of being Somali Canadian or Canadian Somali been an advantage or disadvantage in terms of forming your identity ...

a. How do you negotiate those identities?

b. What are some tensions that arise from embodying more than one identity?

c. How do you see your duality, in terms of embodying more than one identity?

19. And did your role as a cultural broker instill in you more responsibility or made you grow faster since you are taking responsibility for an authority figure?

20. Do you have any siblings? If so were you the only cultural broker in your family?

21. Where places have you acted as a cultural broker? Bank, school, hospital, stores etc

22. I'm guessing you had to go with your parents to school parent meetings?

23. Is there been a situation where you felt you had to protect your parents in terms of not necessarily translating everything directly, in other words sugar-coating?

24. As a cultural broker, did you feel like you had to protect your parent's agency when dealing more powerful authority figures?

25. Do you feel more Canadian or Somalian or is it more hyphenated?

26. Has been an ambassador of language and culture made your awareness or knowledge of both languages and culture stronger?

27. Did you feel pressured to be a cultural broker? 


\section{References}

Abdullahi, M. (2001). Culture and Customs of Somalia (Vol. 2). Westport: Greenwood Publishing Group.

Albanese, p. (2009). Children in Canada Today. Oxford University Press.

Anderson, M. (1999). Children In-Between: Constructing Identities in the Bicultural Family.The Journal of the Royal Anthropological Institute, 13-26.

Atkinson, F., \& Rowland, J. (2001). Accessing Hidden and Hard-to-Reach Populations: Social Research, 1-4.

Bamberg, M. (2002). Narrative analysis. In H. Cooper, APA Handbook of Research in Psychology (pp. 77-94). Washington, DC: APA Psychology.

Bauder, H. (2012). Immigration and Settlement: Challenges, Experiences, and Opportunities. Toronto: Canadian Scholars' Press Inc.

Bauer, E. (2016). Practising kinship care: Children as language brokers in migrant families. Childhood, 22-36.

Bayeh, J. (2010). A "Hyphenated' Identity: Writing About Lebanese Diaspora Fiction Within An Australian Context. Canadian Business \& Current Affairs Database, 124-134.

Bhatia, S. (2002). Acculturation, Dialogical Voices and the Construction of the Diasporic Self. Theory and Psychology, 55-77.

Bhatia, S., \& Ram, A. (2001). Rethinking 'Acculturation' in Relation to Diasporic Cultures and Postcolonial Identities. Human Development, 1-18.

Braun, V., \& Clarke, V. (2006). Using thematic analysis in psychology. Qualitative Research in Psychology, 77-101.

Buriel, E. A. (1998). The Relationship of Language Brokering to Academic Performance, Biculturalism, and Self-Efficacy Among Latino Adolescents. Hispanic Journal of Behavioral Sciences, 283-297.

Burton, L. (2007). Childhood Adultification in Economically Disadvantaged Families: A Conceptual Model. Family Relations, 329-345.

Butler, K. D. (2001). Defining Diaspora, Refining a Discourse. Diaspora: A Journal of Transnational Studies, 189-219.

Castaneda, C. L. (2005). 'Que dice?' Experiences of language brokering among Mexican heritage women. Doctoral dissertation, The University of Utah. 
Cheng, Y. Y. (2012). Re-Conceptualizing Parentified Children from Immigrant Families. Dissertation, 17-58.

Cholewinski, R., \& Taran, P. (2009). Migration, governance and human rights: Contemporary dilemmas in the era of globalization. Refugee Survey Quarterly, 1-33.

Chu, C. M. (1999). Immigrant children mediators (ICM): bridging the literacy gap in immigrant communities. The New Review of Children's Literature and Librarianship, 85-94.

Cila, J., \& Lalonde, R. N. (2015). Language brokering, acculturation, and empowerment: evidence from South Asian Canadian young adults. Journal of Multilingual and Multicultural Development, 498-512.

Cline, T., \& Crafter, S. (2014). Child Language Brokering in School: Final Research Report. Nuffield Foundation, 1-49.

Cline, T., Crafter, S., O'Dell, \& de Abreu, G. (2011). Young people's representation of language brokering. Multilingual and Multicultural Development, 207-220.

Convention and Protocol Relating to The Status of Refugees. (2017, 07 07). Retrieved from UNHCR: http://www.unhcr.org/protection/basic/3b66c2aa10/convention-protocolrelating-status-refugees.html

Coulthard, G. S. (2007). Subjects of Empire: Indigenous Peoples and the 'Politics of Recognition' in Canada. Contemporary Political Theory, 437-460.

Czubinska, G. (2017). Migration as an Unconscious Search for Identity: Some Reflections on Language, Difference, and Belonging. British Journal of Psychotherapy, 159-176.

Davis, e. a. (2004). "A fly in the buttermilk:" Descriptions of university life by successful Black undergraduate students at a predominately white southeastern university. The Journal of Higher Education, 420-445.

Dorner, L. M., \& Orellana, M. F. (2008). It's One of Those Things You Do to Help the Family: Language Brokering and the Development of Immigrant Adolescents. Journal of Adolescent Research, 515-543.

Dorner, L. M., Orellana, M. F., \& Li-Grining, C. P. (2007). "I Helped My Mom," and It Helped Me: Translating the Skills of Language Brokers into Improved Standardized Test Scores. The Univesity of Chicago Press, 451-478.

Edwards, R., \& Holland, J. (2013). What is qualitative interviewing? In G. Crow, 'What is?' Research Method series - What is Qualitative Interviewing (pp. 1-10). Edinburg: University of Edinburg.

Eksner, H. J., \& Orellana, M. F. (2012). Shifting in the Zone: Latina/o Child Language Brokers and the Co-construction of Knowledge. Journal of the Society for Psychological Anthropology, 196-220. 
Esser, H. (2006). Migration, Language, and Integration. Berlin: AKI Research Review 4.

Fisher, L. (2010). Taking an Advocacy With Approach to Better Support Families. perspectives, 11-15.

Frideres, J. (2002). Immigrants, Integration, and the Intersection of Identities. Working Paper. Ottawa: Canadian Heritage, 1-28.

Genkova, A. G., Trickett, E. J., Birman, D., \& Vinokurov, A. (2014). Acculturation and adjustment of elderly émigrés from the former soviet union: A life domains perspective. Psychosocial Intervention, 83-93.

Gibson M.A. (2001). Immigrant adaptation and patterns of acculturation. Human Development, 19-23

Gubrium, J. F., \& Holstein, J. A. (2001). Handbook of interview research: Context and method. In J. F. Gubrium, \& J. A. Holstein, From the individual interview to the interview society (pp. 1-32). London: Sage Publication.

Hall, N., \& Sham, S. (2007). Language Brokering as Young People's Work: Evidence from Chinese Adolescents in England. Language and Education, 17-30.

Hall, S. (1990). In C. I. Diaspora, Identity: Community, Culture, Difference (pp. 1-239). London: Lawrence and Wishart.

Hua, J. M., \& Costigan, C. L. (2012). The Familial Context of Adolescent Language Brokering Within Immigrant Chinese Families in Canada. Journal of Youth Adolescence, 894-906.

Jensen-Hart, S., \& Williams, D. (2010). Blending Voices: Autoethnography as a Vehicle for Critical Reflection in Social Work. Journal of Teaching in Social Work, 450-467.

Johnson, J. M. (2001). In-depth interviewing. In Handbook of interview research: Context and method (pp. 103-119). London: Sage Publication.

Ladilova, A. (2015). Language and Identity of migrants: The role the heritage language in the process of collective identity construction in a migration situation. Language and Dialogue, 176-193.

Lansford, J. E.-D. (2007). Immigrant families in contemporary society. New York: Guilford Press.

Lee, J., Hill-Bonnet, L., \& Raley, J. (2011). Examining the Effects of Language Brokering on Student Identities and Learning Opportunities in Dual Immersion Classroom. Journal of Language, Identity, and Education, 306-326.

Li, P. (2003). Deconstructing Canada Discourse of Immigration Integration. Journal of International Migration and Integration, 315-333

Morales, A., \& Hanson, W. E. (2005). Language Brokering: An Integrative Review of the Literature. Hispanic Journal of Behavioral Sciences, 471-503. 
Ngo, V. (2008). A Critical Examination of Acculturation Theories. Critical Social Work, 1-6.

Nguyen, A. M., \& Ahmadpanah, S. (2014). The Interplay Between Bicultural Blending and Dual Language Acquisition. Journal of Cross-Cultural Psychology, 1215-1220.

Norton, B. (2010). Language and Identity. In N. Hornberger, \& M. S, Sociolinguistics and language education (pp. 349-369). Bristol, UK: Multilingual Matters.

OCASI. (2016). Somali Refugee ResettIment In Canada. Toronto: National Metropolis.

Orellana, M. F., Reynolds, J., Dorner, L., \& Meza, M. (2003). In other words: Translating or "para-phrasing" as a family literacy practice in immigrant households. Reading research quarterly, 12-34.

Pace, S. (2012). Writing the self into research: Using grounded theory analytic strategies autoethnography. Cognitive, Social and Cultural Perspectives, 1-15.

Park, S. M. (2013). Immigrant students' heritage language and cultural identity maintenance in multilingual and multicultural societies. Concordia Working Paper in Applied Linguistics, 30-53.

Peñalva, S. L. (2017). An ethnographic portrait of translingual/transcultural navigation among immigrant children and youth: Voices during Sunday school at a Latino church. Journal of Multilingual and Multicultural Development, 438-452.

Portes A., Rumbaut R.G. Legacies: The story of the immigrant second generation. Berkeley: University of California Press; 2001.

Portes A., Rumbaut R.G. Immigrant America: A Portrait. 3rd Ed. Berkeley: University of California Press; 2006.

Pulido, e. A. (2003). Accessing Assets: Immigrant Youth's Work as Family Translators or "Paraphrasers". Social Problems, 505-524.

Renshon, S. (2011). The Value of a Hyphenated Identity. Chicago: Center for Immigration Studies.

Reynolds, J.F., \& Orellana, M. F. (2009). New Immigrant Youth Interpreting in White Public Space. American Anthropologist, 211-223.

Roche, e. a. (2014). Adolescent Language Brokering in Diverse Contexts: Associations with Parenting and Parent-Youth Relationships in a New Immigrant Destination Area. Journal of Youth Adolescence, 77-89.

Rutherford, J. (1990). A Place Called Home: Identity and the Cultural Politics of Difference. In J. Rutherford, Identity: Community, Culture, and Difference (pp. 1-239). London: Lawrance and Wishart LTD. 
Schwartz, S., \& Unger, J. (2010). Biculturalism \& Contact: When is Biculturalism and when is it adaptive? Commentary on Mistry and Wu. Human Development, 26-32.

Scott, J. L. (2001). A Study of the Settlement Experiences of Eritrean and Somali Parents in Toronto. Toronto: Community Information Centre for the City of York, Eritrean Canadian Community Centre of Metropolitan Toronto and SIWA-Somali Immigrant Women Association.

Sinha, B. R. (2005). Human migration: Concepts and Approaches. Foldrajzi Ertesito, 403-414.

Smokowski, P. R., Rose, R., \&\& Bacallao, M. L. (2008). Acculturation and Latino family processes: How cultural involvement, biculturalism, and acculturation gaps influence family dynamics. Family Relations, 295-308.

Stein, B. N. (1980). The Experiences of Being A Refugee: Insight from Research Literature. International Migration Review.

Suarez-Orozco, M., Darbes, T., Dias, S., \& Sutin, M. (2011). Migration and Schooling. Education and Human Development, 311-328.

Sptizer, D. L. (2006). The Impact of Policy on Somali Refugee Women in Canada. Refugee, Volume 2, 47-54

Trickett, E. J., \& Jones, C. J. (2007). Adolescent culture brokering and family functioning: A study of families from Vietnam. Cultural Diversity and Ethnic Minority Psychology, 143-150.

Tse, L. (1996). Language Brokering Among Latino Adolescents: Prevalence, Attitudes and School Performance. Hispanic Journal Behavioural Sciences, 485-498.

Tufford, L., \& Newman, P. (2010). Bracketing in Qualitative Research. Qualitative Social Work, 80-96.

Valenzuela Jr., A (199). Gender Roles and Settlement Activities Among Children and Their Immigrant Families. American Behavioral Scientist, 720-743.

Weisskirch, R. S. (2005). The Relationship of Language Brokering to Ethnic Identity for Latino Early Adolescents. Hispanic Journal of Behavioral Sciences, 289-299.

Weisskirch, R. S. (2010). Feelings about Language Brokering Family Relation among Mexican American. Early Adolescent, 545-651.

Weisskirch, R. S. (2010). Child language brokers in immigrant families: An overview of family dynamics. MediAzioni 10, 68-87.

Wu, N. H., \& Kim, S. Y. (2009). Chinese American Adolescents' Perceptions of the Language Brokering Experience as a Sense of Burden and Sense of Efficacy. Youth Adolescence, 703-718. 
